Elsevier required licence: $(c)<2018>$. This manuscript version is made available under the CC-BY-NC-ND 4.0 license http://creativecommons.org/licenses/by-nc-nd/4.0/ 


\title{
Eco-driving technology for sustainable road transport: A review
}

Yuhan Huang ${ }^{1, *}$, Elvin C.Y. Ng ${ }^{2,3}$, John L. Zhou ${ }^{1}$, Nic C. Surawski ${ }^{1}$, Edward F.C. Chan ${ }^{2}$, Guang Hong ${ }^{3}$

${ }^{1}$ School of Civil and Environmental Engineering, University of Technology Sydney, NSW 2007, Australia

${ }^{2}$ Jockey Club Heavy Vehicle Emissions Testing and Research Centre, Vocational Training Council, Hong Kong

${ }^{3}$ School of Mechanical and Mechatronic Engineering, University of Technology Sydney, NSW 2007, Australia

\section{Corresponding author:}

Yuhan Huang, $\mathrm{PhD}$

Email: Yuhan.Huang@uts.edu.au

Telephone: +61415040942

\begin{abstract}
Road transport consumes significant quantities of fossil fuel and accounts for a significant proportion of $\mathrm{CO}_{2}$ and pollutant emissions worldwide. The driver is a major and often overlooked factor that determines vehicle performance. Eco-driving is a relatively low-cost and immediate measure to reduce fuel consumption and emissions significantly. This paper reviews the major factors, research methods and implementation of eco-driving technology. The major factors of eco-driving are acceleration/deceleration, driving speed, route choice and idling. Eco-driving training programs and in-vehicle feedback devices are commonly used to implement eco-driving skills. After training or using in-vehicle devices, immediate and significant reductions in fuel consumption and $\mathrm{CO}_{2}$ emissions have been observed with slightly increased travel time. However, the impacts of both methods attenuate over time due to the ingrained driving habits developed over the years. These findings imply the necessity of developing quantitative eco-driving patterns that could be integrated into vehicle hardware so as to generate more constant and uniform improvements, as well as developing more effective and lasting training programs and in-vehicle devices. Current eco-driving studies mainly focus on the fuel savings and $\mathrm{CO}_{2}$ reduction of individual vehicles, but ignore the pollutant emissions and the impacts at network levels. Finally, the challenges and future research directions of eco-driving technology are elaborated.
\end{abstract}

Keywords: Eco-driving; Driving behaviour; Fuel consumption; Emissions; Training and feedback 


\section{Introduction}

Worldwide concerns regarding global warming and fossil fuel depletion have driven many countries to take more serious actions in energy saving and $\mathrm{CO}_{2}$ emissions reduction initiatives. On 12 December 2015, Parties to the United Nations Framework Convention on Climate Change (UNFCCC) reached a landmark agreement - the Paris Agreement - to combat climate change and to accelerate and intensify the actions and investments needed for a sustainable low carbon future. The central aim of the Paris Agreement is to keep global temperature rises well below $2{ }^{\circ} \mathrm{C}$ relative to pre-industrial levels and to pursue further efforts to limit the temperature increase to $1.5{ }^{\circ} \mathrm{C}$ [1-3]. The Paris Agreement entered into force on 4 November 2016 and 175 Parties had ratified it as of April 2018 [4]. To meet the targets of the Paris Agreement, greenhouse gas emissions have to be reduced significantly. Fig. 1 shows the Intended Nationally Determined Contributions (INDCs) as percentages in $\mathrm{CO}_{2}$ reduction by 2030 below 2005 levels for the major $\mathrm{CO}_{2}$ emitting countries [5], together with their shares of global $\mathrm{CO}_{2}$ emissions in 2015 [6]. These major countries accounted for $80 \%$ of global $\mathrm{CO}_{2}$ emissions in 2015. As shown in Fig. 1, on average, most countries are planning to reduce their $\mathrm{CO}_{2}$ emissions by $33 \%$ in 2030 compared to 2005 levels. The transport sector consumes about $20 \%$ of global energy and is responsible for nearly $25 \%$ of global energy related $\mathrm{CO}_{2}$ emissions, $75 \%$ of which are emitted by road transport [7]. Moreover, it is estimated that the energy consumption and $\mathrm{CO}_{2}$ emissions of world transport in 2030 will increase by more than $50 \%$ due to population and economic growth [7, 8]. To achieve this abatement target, the road transport sector must make a significant contribution.

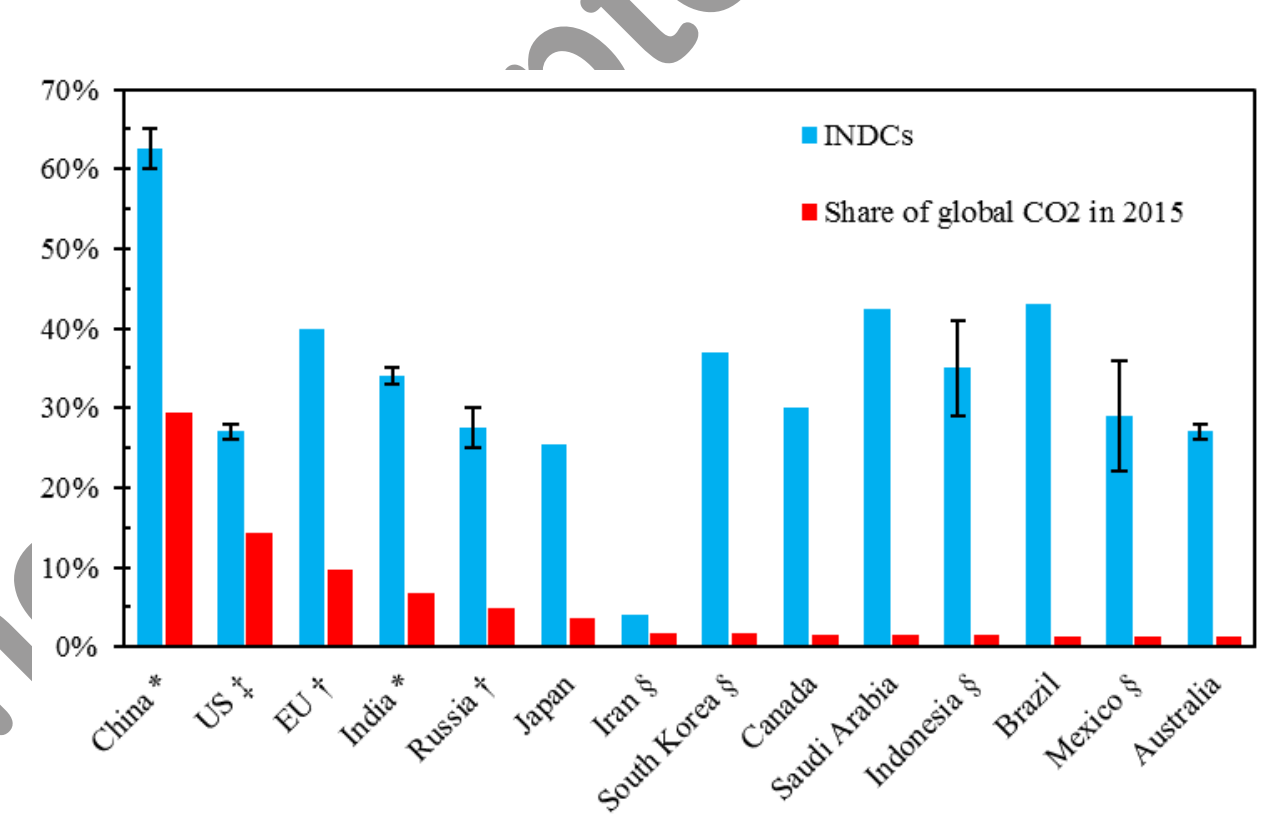

Fig. 1. INDCs as percentages in $\mathrm{CO}_{2}$ reduction by 2030 below 2005 levels for the major $\mathrm{CO}_{2}$ emitting countries, as well as their shares of global $\mathrm{CO}_{2}$ emissions in 2015. Data sources are [5] for INDCs and [6] for shares of $\mathrm{CO}_{2}$. Error bars indicate the ranges of INDCs. Symbols for INDCs: * per unit of GDP, $¥$ target for $2025, \dagger$ base level in 1990, $\S$ base level if business as usual. 
A variety of efforts have been undertaken to improve fuel economy and reduce emissions of on-road vehicles, including more stringent automotive emission standards (e.g. Euro 6/VI standards [9]), new engine and vehicle technologies (e.g. engine downsizing and hybrid/electric vehicles [10, 11]), better fuel quality and renewable fuels (e.g. higher octane rating petrol and bio-fuels [12]). However, an important factor which is often overlooked and may improve vehicle fuel economy significantly is eco-driving technology. The investment for new vehicle technologies and fuels is usually significant and long-term, and an improvement of a few percentages may be considered significant. It was estimated that the potential efficiency improvements of advanced engine and vehicle technologies were only about 4-10\% and 2-8\% respectively [13]. However, the implementation of eco-driving is relatively low-cost and immediate, and the improvement in fuel efficiency can be up to $45 \%$ [14]. Eco-driving is also more cost-effective than fleet retrofit programs (e.g. replacing existing diesel buses with new compressed natural gas ones) [15]. Ecodriving is an initiative which has seen worldwide adoption and investigation in the past decade [16] although great efforts are needed to convert the claimed benefits of eco-driving into real-driving practice with lasting and uniform effects.

The aim of this study is to review and analyse the published studies on eco-driving technology. Specifically this review will cover the major influencing factors, research methods, implementation, and challenges and future research directions of eco-driving.

\section{Major factors of eco-driving}

Eco-driving involves a number of factors and has different definitions or scope in the literature. Sivak and Schoettle [14] defined eco-driving as decisions that a driver could make to influence the fuel economy of light-duty vehicles, ranging from vehicle purchase to post-purchase decisions. These decisions could be categorised into three groups, namely strategic decisions (vehicle selection and maintenance), tactical decisions (route planning and weight) and operational decisions (driving style). Among these decisions, vehicle selection was the single most important factor and post-purchase decisions could not fully compensate for buying a low-efficiency vehicle. Therefore it was suggested that the focus of policy should emphasize vehicle selection [14]. However, fuel economy was not the only factor that determined people's vehicle selection and the post-purchase factors could still contribute a lot, in total up to $45 \%$ reduction of fuel consumption per driver. Based on the concept of behavioural functions, Sanguinetti et al. [17] identified six classes of eco-driving behaviour including driving, cabin comfort, trip planning, load management, fuelling and maintenance. The driving behaviour was further divided into accelerating, cruising, decelerating, waiting, driving mode selection and parking. Zhou et al. [13] identified six groups of factors affecting fuel consumption, namely travel-, weather-, vehicle-, roadway-, traffic- and driver-related factors. A broader scope of eco-driving also involved public education, driving feedback devices, regulation, fiscal incentives and social norm reinforcement [18].

In this study, eco-driving is narrowed to the driving behaviours or the control a driver has over the vehicle during a journey that can influence fuel consumption and emissions. These factors include driving 
speed, acceleration, deceleration, route choice, idling and vehicle accessories (other factors). This is because these factors are the most common and useful eco-driving skills that every driver can implement in practice every day, rather than purchasing a new fuel-efficient car. In addition, changes in the these driving behaviours could lead to significantly higher reductions in fuel consumption and emissions than other behaviours such as better maintenance practices [16].

\subsection{Driving speed}

Constant speed is the optimal speed profile for fuel consumption under various road conditions [19, 20]. Therefore using cruise control when possible is commonly recommended for eco-driving [14, 21,22]. Fuel economy also varies with the cruising speed. This is because each internal combustion engine (ICE) has a speed for optimal fuel economy. Fuel consumption rate firstly decreases with the increase of engine speed due to reduced heat losses, reaches the optimal point and then increases at high speed due to increased friction losses [23]. As a result, the fuel consumption-driving speed curve shows a U-shape. This curve also applies for hybrid and electric vehicles. The optimal speeds for hybrid vehicles are in similar ranges as ICE vehicles, but much lower for electric vehicles [17]. El-Shawarby et al. [24] investigated the effect of constant cruise speed on fuel consumption and emissions based on a sequence of $101-\mathrm{km}$ trips. The results showed that the optimal fuel consumption and emission rates per unit distance were in the range of $60-90 \mathrm{~km} / \mathrm{h}$, with considerable increases outside this range. Wang et al. [25] reported that fuel consumption per unit time was positively correlated with cruise speed and fuel consumption per unit distance was optimal between 50-70 $\mathrm{km} / \mathrm{h}$. Wang and Rakha [26] found that the optimal cruising speed of diesel buses (40-50 km/h) was lower than that of light-duty gasoline vehicles $(60-80 \mathrm{~km} / \mathrm{h})$. The optimal speed for motor efficiency of electric vehicles was in the range of 50-60 km/h [27]. The Australian Department of Environment suggested that fuel consumption increased significantly over $90 \mathrm{~km} / \mathrm{h}$, so that a car would use up to $25 \%$ more fuel at $110 \mathrm{~km} / \mathrm{h}$ than cruising at $90 \mathrm{~km} / \mathrm{h}$ [21]. The US Department of Energy suggested that fuel economy usually decreased rapidly at speed above $80 \mathrm{~km} / \mathrm{h}$ although each vehicle reached its optimal fuel economy at a different speed (or range of speed) [22]. It can be seen that the above suggested optimal cruising speeds are usually below the speed limits on motorways (e.g. $110 \mathrm{~km} / \mathrm{h}$ in NSW Australia). Therefore, reducing motorway speed limits may help reduce fuel consumption and emissions. The European Environment Agency estimated that reducing motorway speed limit from 120 to $110 \mathrm{~km} / \mathrm{h}$ could reduce fuel consumption significantly by $12 \%$ for diesel cars and 18\% for gasoline cars, assuming smooth driving and 100\% compliance with speed limit [28]. In addition, reducing speed limit would also achieve reductions of other pollutants, in particular $\mathrm{NO}_{\mathrm{x}}$ and PM emissions for diesel cars, and safety gains as well. However, fuel savings would be only 2-3\% when relaxing the ideal assumptions to a more realistic situation (speed limit of $110 \mathrm{~km} / \mathrm{h}$ was not fully respected and some speeding occurred). Therefore, to achieve the claimed benefits, it is essential to have tighter enforcement and improve people's understanding on the benefits (fuel savings, emissions reduction and safety gains) and costs (slightly longer travel time) of lower speed limits. In some cases, time saving would have higher priority than reducing fuel consumption and emissions, such as emergency service operations (e.g. ambulances, police cars and fire trucks) and travellers with a tight time schedule. However, in most daily driving tasks, the benefits of eco-driving should outweigh its costs. There is no uniform optimisation 
strategy for all drivers and the drivers should have the right to choose the driving strategy according to their needs.

When it comes to real-world conditions, driving speed cannot be maintained ideally constant and must consider the speed limit, travel time, road grade, traffic signals and traffic flow [29]. Therefore, eco-driving speed is usually recommended at or safely below the speed limit [17, 18, 30]. Many studies have been carried out to estimate the optimal driving speed profile under various real-world conditions, such as congestion levels [31], road grades [32, 33], car-following scenarios [34], signalized roads [35-38], and hybrid electric vehicles [39].

\subsection{Acceleration and deceleration}

A general rule of eco-driving is to change the aggressive driving style, which mainly refers to hard acceleration and deceleration, to a smoother one. The function of acceleration/deceleration is to increase/reduce the driving speed or to start/stop the vehicle. However, there are always more or less efficient ways to do that, and the strategies vary and have no consensus [17, 40]. Most eco-driving programs recommend smooth driving and minimising acceleration and braking [21,22]. The US Department of Energy [22] suggested that aggressive driving could lower fuel economy by $15-30 \%$ at highway speed and $10-40 \%$ in stop-and-go traffic. Drivers could avoid unnecessary acceleration/deceleration by keeping a good distance to the car in front so that drivers can anticipate the road and traffic flow as far ahead as possible [41]. However, a few studies [42, 43] reported that more aggressive acceleration/deceleration to the target speed would save fuel in certain situations. A Swedish eco-driving training program suggested bus drivers accelerate more strongly and start acceleration earlier, which worsened the passengers' comfort [44].

Generally, a smooth driving style saves fuel and increases safety compared to aggressive driving. Ecodriving usually encourages drivers to minimise the use of accelerator and brake pedals by looking ahead at the traffic flow, signals and road grade. This kind of anticipation can help shift the gear more efficiently and avoid unnecessary accelerating, braking, excessive speed and idling. A number of studies have been carried out to investigate the effect of acceleration/deceleration on fuel consumption and emissions. Ericsson [45] analysed the effect of 16 independent driving pattern factors on fuel consumption and emissions. It was found that nine factors played an important role, four of which were associated with acceleration and power demand, three were related to gear changing and two were related to driving speed. Pelkmans et al. [46] reported that acceleration was the dominant factor for a bus in real-city traffic, which shared $35 \%$ of the driving time but was responsible for $70 \%$ of fuel consumption and $60-80 \%$ of $\mathrm{CO}, \mathrm{HC}$ and $\mathrm{NO}_{\mathrm{x}}$ emissions of the entire cycle. El-Shawarby et al. [24] found that aggressive driving at the maximum acceleration capacity had 50\% more fuel consumption, 3\% more $\mathrm{CO}_{2}, 20$ times more $\mathrm{CO}$, six times more $\mathrm{HC}$, but $65 \%$ less $\mathrm{NO}_{\mathrm{x}}$ emissions compared with mild driving (40\% of the maximum acceleration capacity). Chen et al. [47] reported that low-speed conditions with frequent acceleration and deceleration, particularly in congested conditions, were the main factors resulting in high CO and HC emissions. Gallus et al. [48] used several acceleration based parameters to characterise the aggressiveness of driving style, including mean positive acceleration (MPA), relative positive acceleration (RPA) and $95^{\text {th }}$ percentile of velocity multiplied by 
positive acceleration ( $\mathrm{v} \times \mathrm{a}_{\mathrm{pos}} 95 \%$ ). The results showed that $\mathrm{CO}_{2}$ and $\mathrm{NO}_{\mathrm{x}}$ emissions of aggressive driving

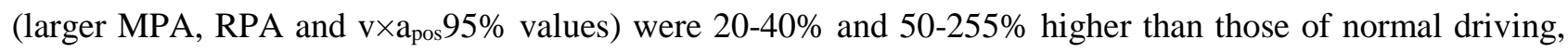
respectively. However, $\mathrm{CO}$ and $\mathrm{HC}$ emissions did not show distinct difference between driving styles. Wang et al. [49] reported that frequent acceleration, especially sharp acceleration, would increase emissions and fuel consumption for buses. Berry [50] found that reducing speed on highways would save roughly the same amount of fuel as reducing acceleration during all driving. However, when it came to individuals, it was suggested that aggressive drivers should focus on reducing acceleration, while less aggressive drivers should focus on reducing speed on highways. The greatest fuel saving could be attained if the most aggressive drivers drove with lower acceleration.

As reviewed above, acceleration and deceleration are the key factors that influence fuel economy and emissions. Therefore, efforts have been devoted to find the optimum acceleration/deceleration values or strategies. Choi and Kim [51] investigated the critical aggressive acceleration values that caused an abrupt increase in fuel consumption for a LPG passenger car. The results showed that the critical values were 2.598 $\mathrm{m} / \mathrm{s}^{2}$ for vehicle starting and $1.4705 \mathrm{~m} / \mathrm{s}^{2}$ during driving. The most efficient use of gears and acceleration strategy was low engine speed and moderate throttle position (50\%) for both petrol and diesel cars [41]. Birrell et al. [30] recommended using smooth and positive acceleration to reach high gears and the desired cruising speed sooner, and using a uniform throttle set at no more than 50\%. Regarding deceleration, they recommended applying engine brake (without changing down through gears) for smooth deceleration and minimising the use of foot brake where appropriate. Sun et al. [52] proposed a speed smoothing scheme for eco-driving to avoid temporarily stopping and unnecessary acceleration/deceleration at road intersections. Hellström et al. [53] proposed a look-ahead control system which decelerated prior to travelling downhill and accelerated before going uphill so that vehicle speed was maintained in a defined range and the time lost at one point was gained at another point. Birrell et al. [54] investigated the effect of a vibrotactile accelerator pedal on driving performance, which was triggered when throttle pedal was pressed by more than $50 \%$. The results showed a significant decrease in the mean acceleration values, as well as maximum and excess throttle use.

\subsection{Idling}

Idling should be minimised because every vehicle achieves zero fuel efficiency $(0 \mathrm{~km} / \mathrm{L})$ when idling [17]. An idling vehicle consumes 0.6-5.7 L/h fuel depending on the vehicle type, engine size, fuel type and load [55]. It was estimated that idling wasted about 22.7 billion litres fuel in the US annually, half of which was contributed by personal vehicles [56]. Eliminating unnecessary idling of personal vehicles would be the

same as taking 5 million vehicles off the road in terms of saving fuel and reducing emissions [56]. Idling also produces high pollutant emissions of $\mathrm{CO}, \mathrm{HC}, \mathrm{NO}_{\mathrm{x}}$ and $\mathrm{PM}$ [57].

Idling time can be reduced in many ways. Firstly, it is needed to update people's understanding and knowledge on idling. Modern cars do not need to idle to warm up the engine or catalytic converter [56]. Reaching the ideal operating temperature is achieved more quickly by driving than idling. Even on the coldest days, most manufacturers recommend avoiding idling and driving off gently for about $30 \mathrm{~s}$ to warm 
up the engine. Similarly, modern cars do not suffer damage by being turned on and off, and $10 \mathrm{~s}$ idling has more fuel consumption and emissions than stop-and-restart does $[21,56]$. It was suggested that the engine should be turned off when waiting time was expected to be longer than $1 \mathrm{~min}$ and the fuel economy could be improved by $19 \%$ if turning the engine off for 10 2-min idling periods on a 10-mile course [14]. However, a survey showed that the average total idling time of American drivers was 16.1 min per day [58]. At least $80 \%$ of the respondents thought that idling a vehicle for more than $30 \mathrm{~s}$ was better than stop-and-restart. The average respondent believed that a vehicle should be idled for at least $2 \mathrm{~min}$ before driving in mild weather and even longer in cool or cold weather. Consequently, a large amount of fuel was wasted in idling due to inaccurate or outdated knowledge. A recent online survey also demonstrated that although the majority of people were aware of eco-driving and had a positive attitude towards it, their knowledge of specific fuel saving behaviour was generally low [59]. Therefore, like the concept of eco-driving, changing people's idling behaviour is a more efficient, faster and cheaper way to save fuel than idling reduction technologies.

The above knowledge mainly targets idling off road, such as avoiding long idling before driving or stopping, and turning the engine off while waiting for passengers. However, drivers usually have less control over idling in traffic and it may be inconvenient or even unsafe to turn off the engine. This kind of idling can be reduced or avoided by more efficient speed, accelerating, decelerating and routing behaviours. By looking ahead at the changes in traffic flow or signals, idling time in congested traffic or intersections could be reduced by decelerating earlier and more smoothly (releasing throttle and using engine brake rather than foot brake) and avoiding unnecessary accelerating and hard braking again, which save fuel during both driving and idling. Mahler and Vahidi [60] proposed an optimal velocity-planning algorithm to minimise the idling time behind red lights and maximise the chance of going through green lights based on probabilistic trafficsignal timing models. The model showed a $61 \%$ increase in fuel economy in a motivating case study (ideal and best condition), but $16 \%$ for fixed-time signals and $6 \%$ for actuated signals compared with the uninformed drivers. Mandava et al. [61] developed an algorithm to provide drivers dynamic speed advice based on real-time signal information, so that drivers could maximise the probability of passing through green lights without idling and adjust their speed smoothly to minimise emissions from sharp acceleration and deceleration. The algorithm showed a 12-14\% reduction in energy and emissions. Li et al. [62] proposed an advisory system to alert drivers to release the throttle earlier and brake gently in response to a change of traffic signal. The results showed $8 \%$ of fuel savings in medium congested traffic. Idling time at intersections, congestions and accidents could be reduced or avoided by eco-routing devices [63, 64]. New engine technologies can also help reduce idling in traffic. For example, many new vehicles are now equipped with stop-start technology which turns off the engine whenever idling and restarts comfortably when drivers touch the accelerator pedal $[65,66]$. Fonseca et al. [67] reported that a vehicle with a stop-start system had more than $20 \% \mathrm{CO}_{2}$ reduction than a similar vehicle without stop-start technology, partly due to zero idling emissions. Hybrid vehicles turn off the engine when idling and even at low driving speed. 


\subsection{Route choice}

Route choice is another major factor that determines the total fuel consumption and emissions for a given origin-destination trip. Once the route is chosen, the aforementioned eco-driving factors will be largely limited by the route characteristics. Route choosing involves a number of factors including travel time, distance, speed limit, and road and traffic conditions. There are usually several routes for a given origindestination trip. Mostly, a driver would choose a route with either the shortest travel distance or the fastest travel time. However, the shortest or fastest route is not always the best choice in terms of fuel consumption and emissions [68-70]. A Swedish study found that $46 \%$ trips of the drivers' spontaneous choices were not the most fuel-efficient routes and $8.2 \%$ of fuel could be saved by using a fuel-optimised navigation system [71]. This is because the fastest route may be longer and include highways that do not allow the vehicles to run at the eco-driving speed $(50-90 \mathrm{~km} / \mathrm{h}$, as discussed in Section 2.1$)$, thus resulting in higher fuel consumption. While the shortest route may contain congested traffic, leading to higher fuel consumption and longer travel time. Trade-off is needed between travel time, distance and fuel consumption. Zeng et al. [72] developed an eco-routing approach to determine the path with minimum $\mathrm{CO}_{2}$ emissions while satisfying time constrains. They found that the average reduction of $\mathrm{CO}_{2}$ could reach $11 \%$ when the travel time buffer was $10 \%$. Kuo [73] proposed a model to calculate the fuel consumption for a time-dependent routing problem. The results showed that the proposed method could have $25 \%$ reduction in fuel consumption over the fastestroute method and $23 \%$ over the shortest-route method. Ahn and Rakha [74] found that eco-routing system typically reduced travel distance but not necessarily travel time.

Road type and grade could influence fuel economy and emissions significantly. Road type determines the speed, acceleration and deceleration profiles, and consequently fuel economy. For example, the average fuel economy of highways with an $80 \mathrm{~km} / \mathrm{h}$ speed limit or higher is about $9 \%$ better than other roads [14]. Choosing a flat and constant speed limit road is not only safer, but also saves fuel. Gallus et al. [48] reported that, with accelerations within $\pm 0.1 \mathrm{~m} / \mathrm{s}^{2}, \mathrm{CO}_{2}$ and $\mathrm{NO}_{\mathrm{x}}$ emissions showed a linear correlation with road grade for all urban, rural and motorway conditions. The step from 0 to $5 \%$ road grade led to a $65-81 \%$ increase in $\mathrm{CO}_{2}$ and 85-115\% increase in $\mathrm{NO}_{\mathrm{x}}$. Jin et al. [75] reported that, for a 250-metre freeway segment with the same initial speed, final speed and trip time, the fuel consumption of a $6 \%$ grade route was $86 \%$ and $171 \%$ higher than those of 0 and $-6 \%$ grade routes, respectively. Higher road grade required the vehicle to run at high engine load condition more frequently, causing higher fuel consumption and emissions. A small proportion of the entire trip with high engine load condition was responsible for a significant amount of trip emissions and fuel consumption [70]. Therefore, routes with large road grade should be avoided. It was reported that fuel economy of flat routes would be $15-20 \%$ better than that of hilly roads [76].

Traffic conditions should also be considered when choosing the route. A fuel efficient route should avoid congested roads and minimise idling time at intersections or traffic lights. Several studies had been performed regarding this aspect. Boriboonsomsin et al. [69] presented an eco-routing navigation system based on the historical and real-time traffic information. The results showed that, compared with the fastest route, an eco-route would provide $12-14 \%$ average fuel savings but incur 16-22\% longer travel time 
depending on the trip distance. Sun and Liu [52] developed an eco-routing algorithm by considering vehicle arrival and signal status information in a signalized traffic network. On average, a $20 \%$ reduction of CO emissions was observed compared with a traditional shortest path algorithm. Yao and Song [63] proposed an eco-routing algorithm based on locally collected vehicle operation and emissions data and a dynamic traffic information database. Compared with the fastest route, the eco-route could reduce fuel consumption by 2.27.4\% depending on the vehicle type, travel distance and traffic flow. The maximum fuel savings could be achieved under heavy congestion and 10-15 km conditions. Nie and Li [64] presented an eco-routing model to find the path with the minimum total travel time and fuel costs, which considered the major acceleration events associated with link changes and intersection idling. The results showed that vehicle characteristics (especially weight and engine displacement), turning movements and acceleration had significant influence on the choice of the eco-route. Some of the above studies have mentioned that the amount of fuel savings on the chosen eco-route was dependent on vehicle type [63, 64], which should also be considered in eco-routing algorithms. Ahn and Rakha [70] found that each vehicle type would have a different optimal route for HC and $\mathrm{CO}$, but the same route for $\mathrm{NO}_{x}, \mathrm{CO}_{2}$ and fuel consumption. Bandeira et al. [77] reported that eco-route differed according to the vehicle model and emissions estimation method.

A commonly ignored factor in eco-routing studies was how individual vehicle's route choice would affect others at network levels. The above studies mostly investigated the effectiveness of eco-routing system for individual vehicles. Rakha and Ahn used an INTEGRATION eco-routing framework to evaluate the network-wide impacts $[74,78]$. The results showed that the system-wide benefits of eco-routing generally increased with the increase of system market penetration rate [74]. However, Garcia-Castro et al. [79] reported that a high percentage of eco-drivers would have negative effects on global emissions under high traffic demand conditions because higher headways and smooth acceleration/deceleration increased congestion. Moreover, it is possible that if too many drivers are directed into the same route, then the initially calculated eco-route may become congested and thus not be fuel efficient [69]. This will need not only realtime traffic information, but also communication between vehicles. Jiang et al. [80] reported that the benefits of eco-driving increased with the market penetration rate of connected and automated vehicles until levelling off at a $40 \%$ penetration rate.

\subsection{Other factors}

Air conditioning system uses extra fuel and eco-driving principles suggest using it conservatively. It is the single largest auxiliary load on a vehicle [81]. An air conditioner compressor could use up to 5-6 $\mathrm{kW}$ power from the engine, equivalent to driving a vehicle steadily at $56 \mathrm{~km} / \mathrm{h}$. It was estimated that 13.5 billion litres fuel (or $3 \%$ fuel consumption) could be saved in the US by reducing the use of air conditioners by $50 \%$ [82]. Experimental results showed that a small passenger car consumed more fuel with maximum cooling than with windows-down when cruising speed was between $64-113 \mathrm{~km} / \mathrm{h}$ [83]. However, fuel consumption with windows-down overtook air conditioner at $129 \mathrm{~km} / \mathrm{h}$ due to the increased aerodynamic drag. Therefore, rolling windows down for ventilation and cooling is more efficient at low speed (e.g. on city streets) but air conditioner becomes more efficient at high speed (e.g. on motorways) if it is not operated at the maximum 
cooling load. Parking the car in the shade in hot weather and in a warm place in cool weather could save fuel from the engine warm-up and usage of air conditioner. Using other vehicle accessories, such as cabin and seat heating, headlights, entertainment systems and cigarette lighters, also increases fuel consumption. Conservative use of these features is recommended [17]. However, generally their effect is insignificant and the drivers' safety and comfort should not be compromised for eco-driving.

Other factors influencing fuel consumption include vehicle weight, tyre pressure, maintenance and aerodynamic drag $[14,17,21,22,41]$. Vehicle weight should be minimised by removing unnecessary items. $45 \mathrm{~kg}$ of extra weight can increase fuel consumption by $1-2 \%$ and the impact is more significant for small vehicles $[16,22]$. It was estimated that each additional pound of average passenger weight would increase US petrol consumption by more than 148 million litres per year [84]. Proper maintenance can reduce fuel consumption. Fuel consumption could increase $1-2 \%$ by driving with under-inflated tires, by $4 \%$ with a poorly tuned engine, and by as much as $40 \%$ with a faulty oxygen sensor [14]. Aerodynamic drag should be minimised. Additional parts on the exterior of a vehicle or having the windows open could increase air resistance and fuel consumption by over $20 \%$ at high driving speed [21]. Alarge blunt roof cargo box can reduce fuel economy by $2-25 \%$ and a rear cargo box or tray can reduce fuel economy by $1-5 \%$ depending on the driving speed [22]. Therefore, it is recommended to store necessary cargo in the vehicle rather than on external racks, to use rear racks rather than roof racks, and to use aerodynamic racks and to pack cargo tight and low if roof cargo cannot be avoided [17]. However, drivers usually do not have much control over these factors during a trip and the chance of implementing these skills is relatively low.

\subsection{Comparison of eco-driving factors}

Fig. 2 compares the ranges of percentages of fuel savings or $\mathrm{CO}_{2}$ reduction contributed by each ecodriving factor. Savings in fuel consumption are taken from experimental or numerical studies for a given origin-destination trip. Some data indicating the potential benefits of a single factor in ideal or extreme conditions is not comparable and thus excluded. For example, although fuel consumption of a $6 \%$ grade road is $86 \%$ and $171 \%$ higher than those of $0 \%$ and $-6 \%$ grade roads [75], there are no three such routes containing only uphill, flat or downhill roads for a given origin-destination trip. It should also be noted that eco-driving factors are not independent and mostly overlap with each other, as shown in Table 1. As shown in Fig. 2, the primary eco-driving factor is acceleration/deceleration, contributing to 3.5-40\% fuel savings or $\mathrm{CO}_{2}$ reduction. This justifies the effectiveness of avoiding aggressive driving style that is commonly recommended in eco-driving programs. Driving speed and route choice could contribute to 2-29\% and 2.2$25 \%$ fuel savings, respectively. They are followed by idling reduction (6-20\%). Other factors (indicated by ${ }^{\dagger}$ )

that the drivers have control over during a trip (e.g. air conditioner) have insignificant effect on fuel consumption $(<10 \%)$. Although a faulty oxygen sensor can cause up to $40 \%$ more fuel consumption, such factors (indicated by are not frequent and drivers have no control over them during a trip. Therefore, the majority of eco-driving studies focused on the driving behaviours of acceleration, deceleration, driving speed, route choice and idling. 


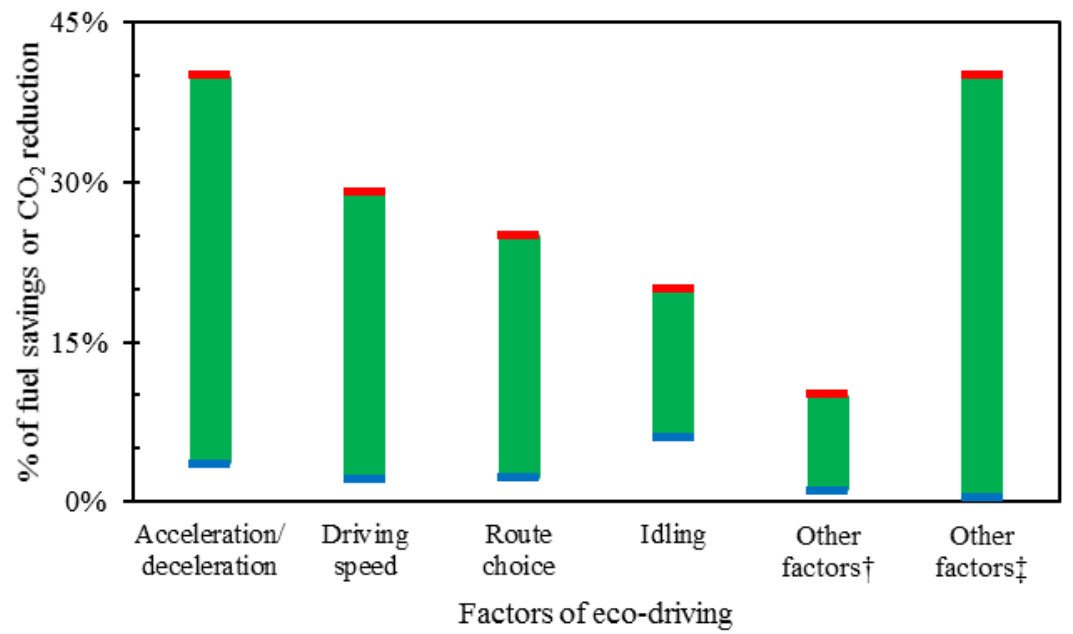

Fig. 2. Ranges of percentages of fuel savings or $\mathrm{CO}_{2}$ reduction contributed by each eco-driving factor. Data are derived from [22, 24, 48, 53] for acceleration/deceleration, [21, 22, 28, 32-38] for driving speed, [14, 60 $62,67]$ for idling, $[14,63,69-74,76,78]$ for route choice, $[16,22,82]$ for other factors that drivers have control over and $[14,17,21,22]$ for other factors ${ }^{\ddagger}$ that drivers have no control over.

Table 1. Driving parameters included in each eco-driving factor.

\begin{tabular}{|c|c|c|}
\hline Eco-driving factors & Parameters considered & Refs. \\
\hline Driving speed & $\begin{array}{l}\text { Cruise control, vehicle speed, speed limit, compliance } \\
\text { of speed limit, travel time, traffic flow, traffic signal, } \\
\text { fuel type, road grade, gear shifting. }\end{array}$ & {$[21,22,28,32-38]$} \\
\hline $\begin{array}{l}\text { Acceleration/ } \\
\text { deceleration }\end{array}$ & $\begin{array}{l}\text { Aggressiveness, anticipation, headways, traffic flow, } \\
\text { traffic signal, road grade, throttle position, engine/foot } \\
\text { brake. }\end{array}$ & {$[22,24,48,53]$} \\
\hline Idling & $\begin{array}{l}\text { Knowledge on idling, anticipation, traffic flow, traffic } \\
\text { signal, vehicle speed, acceleration/deceleration, route } \\
\text { choice, stop-start and hybrid technologies. }\end{array}$ & {$[14,60-62,67]$} \\
\hline Route cho & $\begin{array}{l}\text { Travel time, travel distance, when to travel, road } \\
\text { grade, road type, speed limit, congestion, idling at } \\
\text { intersections, network-wide impacts, market } \\
\text { penetration rate, vehicle type. }\end{array}$ & {$[14,63,69-74,76,78]$} \\
\hline & $\begin{array}{l}\text { Air conditioner, excess weight }(45 \mathrm{~kg}) \text {, aerodynamic } \\
\text { drag (windows). }\end{array}$ & {$[16,22,82]$} \\
\hline & $\begin{array}{l}\text { Under-inflated tires ( } 1-5 \mathrm{psi}) \text {, out of tune engine, } \\
\text { faulty oxygen sensor, aerodynamic drag (external } \\
\text { cargos). }\end{array}$ & {$[14,17,21,22]$} \\
\hline
\end{tabular}

Other factors $^{\dagger}$ : factors that drivers have control over during driving and can be frequently applied.

Other factors ${ }^{\ddagger}$ : factors that drivers have no control over during driving and are not frequent.

\section{Research methods for eco-driving}

This section reviews the methods used to investigate eco-driving technology, including laboratory testing, on-road experiments and numerical modelling. Their mechanisms, advantages/disadvantages and applications are discussed and compared. 


\subsection{Laboratory experiments}

Fuel consumption and emissions for different driving styles can be measured in laboratory using a chassis dynamometer, engine dynamometer or driving simulator. Laboratory experiments are performed under controlled conditions and their accuracy and repeatability are relatively high.

\subsubsection{Engine dynamometer}

Engine dynamometers are commonly used to investigate the engine power and emission characteristics. In an engine dynamometer test cell, the engine driveshaft is directly coupled to the dynamometer shaft. An absorption unit is used to absorb any specific load and measure the engine power, torque and speed. In engine dynamometer testing, the engine and exhaust after-treatment system are required to be removed from the vehicle and the tests follow the procedures specified in regulations [85]. Various engine operating parameters can be monitored in real-time, including exhaust emissions, fuel consumption, torque, speed, incylinder pressure, etc. The major advantage of an engine dynamometer is that the test cell can be climatically controlled (i.e. ambient temperature and humidity) to simulate driving under a wide range of climatic conditions. The operator has full control of all the engine parameters. Thus, engine dynamometer testing can be conducted to investigate the impacts of driving styles and ambient conditions on emissions and fuel consumption. Furthermore, the engine driveshaft is directly connected to the dynamometer so the results are not affected by transmission and driveline power losses. Therefore, the accuracy and repeatability of engine dynamometer test are relatively high. The limitations of engine dynamometer testing are that it does not fully represent the performance of a complete vehicle and the range of test conditions is limited although realworld engine load test cycles can be run on modern engine test benches by simulating the vehicles on-road driving dynamics [86]. Furthermore, the fuel consumption and emissions of entire vehicle fleets cannot be represented by engine dynamometer testing as usually only a few engines in each vehicle type are tested.

\subsubsection{Chassis dynamometer}

Chassis dynamometers enable operators to simulate the resistive load on vehicle wheels. They consist of three main components, namely the load cell (absorption unit), the roller set and the power and torque indication system. During chassis dynamometer testing, the vehicle is tied down and placed on a set of rollers which are coupled to the dynamometer load cell or a belt drive system. Thus, load can be applied to the vehicle to simulate real-world driving resistance. The driving cycles and load can be controlled by operators, which are mainly transient cycles such as the New European Driving Cycle (NEDC) and Federal Test Procedure (FTP). These cycles are pre-defined driving profiles that operators have to attempt to emulate during testing. Operators must anticipate and follow the speed within $\pm 2 \mathrm{~km} / \mathrm{h}$ and time within $\pm 1 \mathrm{~s}$ [87]. The vehicle fuel consumption and exhaust emissions are continuously measured and recorded along with driving parameters. As chassis dynamometers are built in laboratory and designed to meet regulatory standards, the testing results are highly precise and reliable. Moreover, test cycles, road resistance and climate conditions can be fully controlled by operators, thus the test results are not affected by real-world driving factors and the repeatability is relatively high. Chassis dynamometer testing can evaluate the impacts of driving behaviours on emissions and fuel economy, which will be analysed for further development of eco-driving technology. 
On the other hand, the range of test conditions such as steep road gradients are limited in chassis dynamometer testing. Thus, chassis dynamometer testing cannot represent real driving. Furthermore, driving resistance that simulates road load is generated from vehicle coast down test under artificial conditions. So that vehicle emissions and fuel consumption are lower when compared to real driving results [88].

\subsubsection{Driving simulator}

Driving simulators are mainly built in laboratory to study driving behaviours, to provide eco-driving training, and to evaluate new eco-driving training programs and in-vehicle devices. A driving simulator mainly consists of a fixed-base car mock-up with a steering wheel, acceleration and brake pedals and indicators. Road scenarios are displayed on a screen, which provide the road environment and traffic information to the driver. Driving behaviours are continuously monitored and fuel consumption and emissions are calculated accordingly. The major advantage is that driving simulators offer a safe and effective method for examining various factors on the driver performance [89]. Safety issues and traffic accidents are not a concern in a laboratory driving simulator study. The driving behaviours are recorded and used to improve the performance of individual drivers. Real-time driving information are displayed on the screen to drivers so that they can well understand the impacts of their behaviours on emissions and fuel consumption during the experiment. The limitation of driving simulators is that road and traffic conditions are pre-defined and fixed. Eco-driving studies on driving simulators usually only have a few runs to test the introduction of new training programs or in-vehicle devices. Real-world traffic and road conditions are not included. Furthermore, the results are highly dependent on the simulator program which calculates the emissions and fuel consumption corresponding to different vehicle operation conditions. The use of driving simulators may also cause simulator sickness mostly due to an incongruity of sensory input with conflicting signals from simulated and actual motion [90].

\subsection{On-road experiments}

Emissions and fuel consumption measurements under on-road conditions provide valuable data for the actual driver performance of eco-driving. On-road experiments are typically less accurate and repeatable than laboratory testing [91]. Moreover, on-road experiments are highly affected by the uncertainties in traffic conditions, driver behaviours and transient operation due to the absence of standard testing cycles [86]. The commonly used on-road research methods for eco-driving include portable emissions measurement system (PEMS), data logger, odometer reading and fuel use, and surveys.

\subsubsection{PEMS}

A PEMS is a mobile emission measurement instrument that is used on-board the target vehicle to test under real driving conditions. A PEMS integrates advanced emission analysers, an exhaust flow meter, a weather station and a GPS system, and connects with the on-board diagnostics (OBD) system of the vehicle to acquire the driving parameters such as vehicle and engine speeds. A PEMS is installed either in the cabin or in the trunk of the test vehicle. Heated sample lines and exhaust flow measurement system are directly connected to the tailpipe. The sampling line is pre-heated to $190^{\circ} \mathrm{C}$ to avoid the condensation of $\mathrm{HC}$. Exhaust 
emissions, flow rate and temperature can be monitored in real-time together with the engine, vehicle and ambient parameters. A PEMS is well utilised and developed because the upcoming Euro- $6 \mathrm{c}$ regulation will include Real Driving Emissions (RDE) as a new and additional type approval test for new vehicles [92]. The major advantage is that a PEMS can provide second-by-second emissions and fuel consumption data during real-world driving. It can be installed into different categories of vehicles to build up a large database under a wide range of driving conditions for further development of eco-driving technology. The effect of driving style on fuel consumption and emissions can be analysed. In addition, the impacts of road grade can be investigated [48], which would be difficult to replicate in laboratory testing. On the other hand, a PEMS usually measures a limited range of pollutants which are less comprehensive than laboratory testing can achieve. The total weight of a PEMS including accessories is about 100-500 kg which can affect the measurement results, especially for light weight vehicles (e.g. $45 \mathrm{~kg}$ of extra weight could increase fuel consumption by $1-2 \%[16,22])$. Moreover, the repeatability and accuracy of PEMS measurements are lower than laboratory testing due to the traffic conditions, driving behaviours and ambient conditions in a real driving.

\subsubsection{Data logger}

Data loggers are designed to collect the vehicle state and driver operation data under real driving conditions. Data loggers are plugged into the OBD II or control area network (CAN) of a vehicle to collect the vehicle speed, engine speed, fuel consumption, GPS and emissions data. OBD II is a standard port to provide real-time data of driving parameters and has been adopted by the US EPA since 1996 [93]. The major advantage of data loggers is that they can be simply connected with an OBD II or CAN and collect data during normal driving. They can minimise the effect of the added device mass on the measured results compared to a PEMS. Most vehicles manufactured after 1996 should have OBD II ports. The data collected can be used to investigate the impacts of driving behaviours on emissions and fuel consumption. In addition, data loggers can be used on a large number of vehicles during long-term normal daily driving at a low cost. On the other hand, the data available from OBD II or CAN differs by manufacturer, vehicle model and type. Not all driving parameters are available as some may not be found in OBD II or CAN data stream.

\subsubsection{Odometer reading and fuel use}

Eco-driving has been already implemented in normal daily driving. To evaluate its effectiveness, fuel consumption can be manually logged by paper forms, fuel cards and company records (how frequently and how much fuel is refilled) and vehicle usage can be recorded via the odometer readings. The advantage of this method is that it is relatively simple and inexpensive. It is applicable to a large number of vehicles and feasible for long-term studies. In addition, this method does not have impact on the driving behaviours. However, the limitation is that human errors may occur in recording the fuel use and mileage, and drivers may forget to record the data at gas stations. Another limitation is that the data available is very limited, mainly the fuel use and mileage. The calculated fuel consumption rates are only mean values in certain periods. 


\subsubsection{Surveys}

Surveys are assigned to drivers after they are involved in eco-driving programs. The levels of fuel savings and emissions reduction are strongly dependent on drivers' motivation, attitude, acceptance, knowledge and behavioural change. Surveys are aimed to understand these factors. The advantages of surveys are relatively simple and inexpensive. Furthermore, the feedback of drivers' experience can be used to improve the eco-driving training programs and in-vehicle devices. The major limitation of surveys is that the information collected is very limited and no quantitative data on fuel consumption or emissions is available.

\subsection{Numerical modelling}

Numerical modelling is widely used to evaluate the performance of new eco-driving and eco-routing algorithms. Numerical models predict the fuel consumption and emissions as a result of different driving behaviours. Based on transparency, Zhou et al. [13] classified fuel consumption models into white-box, greybox and black-box models, with ascending simplicity and descending accuracy. By comparing the model efficiency and accuracy, the grey-box models are recommended for eco-driving and eco-routing systems [13]. The major advantage is that numerical modelling can investigate the effectiveness of new eco-driving strategies or algorithms without conducting field experiments, saving greatly in both research time and cost. However, the limitation is that the results are less accurate and reliable than those of laboratory and on-road experiments. A model may only consider a few driving parameters (input variables) and ignore others that also have impacts on driver performance. In addition, the results are limited as well. Some models may only predict fuel consumption [25, 94-96] while some may be able to predict a few common emissions (mostly $\mathrm{CO}_{2}, \mathrm{CO}, \mathrm{HC}$ and $\left.\mathrm{NO}_{\mathrm{x}}\right)[51,52,70,72]$.

\subsection{Comparison of research methods and their applications}

Table 2 summarises the mechanisms, advantages and limitations of the research methods used for ecodriving. As shown in Table 2, each method has its own advantages and disadvantages, which determine their applications in eco-driving research. Engine and chassis dynamometers are highly accurate and repeatable. They are commonly used for type-approval or inspection and maintenance (I/M) programs. Engine and chassis dynamometer testing results are also valuable for developing numerical models. Driving simulator is a safe and effective method to design and evaluate new eco-driving training strategies and in-vehicle devices. A PEMS measures second-by-second fuel consumption and emissions data, along with the driving, vehicle and ambient parameters under real-world driving. This dataset enables detailed analysis to be performed on the effect of each driving parameter on driver performance, thus to identify fuel-efficient and low-emission behaviours for developing more effective eco-driving strategies. Data loggers are suitable for evaluating the effectiveness of eco-driving training programs or in-vehicle devices during normal driving in the long-term and at large-scale due to the low-cost, simple setup and limited maintenance/supervision required. Odometer readings and fuel records are also suitable for long-term and large-scale studies. The cost is lower while the data collected is much more limited compared to data loggers. Surveys are used to understand drivers' attitude, knowledge, motivation and acceptance of eco-driving training programs and in-vehicle devices, 
which cannot be acquired by other methods. Numerical modelling is usually used to design and evaluate new eco-driving and eco-routing algorithms without performing field tests, which helps reduce both the research time and cost.

Table 2. Comparison of eco-driving research methods.

\begin{tabular}{|c|c|c|c|}
\hline Method & Mechanism & Advantages & Disadvantages \\
\hline $\begin{array}{l}\text { Engine } \\
\text { dynamometer }\end{array}$ & $\begin{array}{l}\text { Measures engine operation } \\
\text { parameters by applying simulated } \\
\text { load via dynamometer }\end{array}$ & $\begin{array}{l}\text { High accuracy and repeatability } \\
\text { Climatically controlled } \\
\text { Full control on engine }\end{array}$ & $\begin{array}{l}\text { Not real-world data } \\
\text { Not a complete vehicle } \\
\text { Small scale studies } \\
\text { High cost }\end{array}$ \\
\hline $\begin{array}{l}\text { Chassis } \\
\text { dynamometer }\end{array}$ & $\begin{array}{l}\text { Measures vehicle operation } \\
\text { parameters by applying simulated } \\
\text { resistive load via chassis roller }\end{array}$ & $\begin{array}{l}\text { High accuracy and repeatability } \\
\text { Climatically controlled } \\
\text { Large degree of control }\end{array}$ & $\begin{array}{l}\text { Not real-world data } \\
\text { Limited road gradient } \\
\text { Small scale studies } \\
\text { High cost }\end{array}$ \\
\hline $\begin{array}{l}\text { Driving } \\
\text { simulator }\end{array}$ & $\begin{array}{l}\text { Records driver behaviours and } \\
\text { performance data in driving } \\
\text { simulator system }\end{array}$ & $\begin{array}{l}\text { No safety issues } \\
\text { Low cost }\end{array}$ & $\begin{array}{l}\text { Driving conditions are pre-defined } \\
\text { Not real-world data } \\
\text { Simulator sickness } \\
\text { Short-term studies }\end{array}$ \\
\hline PEMS & $\begin{array}{l}\text { Measures vehicle operation } \\
\text { parameters by carrying instrument } \\
\text { on-board the target vehicle }\end{array}$ & $\begin{array}{l}\text { Acceptable accuracy } \\
\text { Real-world data } \\
\text { Wide driving and ambier }\end{array}$ & $\begin{array}{l}\text { Added weight may basis results } \\
\text { Limited repeatability } \\
\text { Small-scale and short-term studies }\end{array}$ \\
\hline Data logger & $\begin{array}{l}\text { Reads vehicle and engine operation } \\
\text { parameters from OBD II or CAN }\end{array}$ & $\begin{array}{l}\text { Low cost, fast and easy setup } \\
\text { Long-term and large-scale studies } \\
\text { No impact on driver performance } \\
\text { Real-world data }\end{array}$ & $\begin{array}{l}\text { Limited accuracy and repeatability } \\
\text { Available data is limited and differs by } \\
\text { vehicle model }\end{array}$ \\
\hline $\begin{array}{l}\text { Odometer } \\
\text { reading and } \\
\text { fuel record }\end{array}$ & $\begin{array}{l}\text { Records odometer reading and } \\
\text { fuelling frequency by drivers or } \\
\text { company }\end{array}$ & $\begin{array}{l}\text { Low cost and simple } \\
\text { Long-term and large-scale studies } \\
\text { No impact on driver performance } \\
\text { Real-world data }\end{array}$ & $\begin{array}{l}\text { May miss some records (human factors) } \\
\text { Very limited information recorded } \\
\text { Low accuracy and repeatability }\end{array}$ \\
\hline Survey & $\begin{array}{l}\text { Receives feedback from drivers af } \\
\text { eco-driving programs }\end{array}$ & $\begin{array}{l}\text { Low cost and simple } \\
\text { Large scale studies }\end{array}$ & $\begin{array}{l}\text { No quantitative data on fuel consumption } \\
\text { and emissions }\end{array}$ \\
\hline $\begin{array}{l}\text { Numerical } \\
\text { modelling }\end{array}$ & $\begin{array}{l}\text { Predicts effect of driving behaviour } \\
\text { on fuel consumption and emissions } \\
\text { by numerical models }\end{array}$ & $\begin{array}{l}\text { Low cost } \\
\text { Shortens research cycle }\end{array}$ & $\begin{array}{l}\text { Not real-world data } \\
\text { Low accuracy and reliability } \\
\text { Limited factors considered } \\
\text { Limited output data }\end{array}$ \\
\hline
\end{tabular}

\section{Implementation of eco-driving}

\subsection{Training programs}

The purposes of eco-driving training programs are to provide drivers with the knowledge (theoretical training) and skills (practical training) to drive more fuel efficiently. Table 3 summaries the published ecodriving training programs which compared the fuel consumption before and immediately after (or a certain period after) training. Some studies also included a control group to better assess the training effects. As shown in Table 3, the percentage of fuel savings is generally in the range of $2-15 \%$, varying significantly between programs and individuals. Eco-driving programs usually included theoretical training, practical training or their combination. The training results have not reached a consensus and sometimes may be even conflicting. This is because each program varies greatly in eco-driving strategies, vehicle categories, trainees 
and driving conditions. Andrieu and Pierre [97] compared the effects of simple advice and eco-driving training on driving behaviours. Their results showed that the average fuel consumption decreased by providing simple advice (12.5\%) was slightly higher than that by training (11.3\%). However, the routes and vehicles used for the two methods were different. Jeffreys et al. [98] compared the effectiveness of five ecodriving interventions with increasing intensity, including (1) $1 \mathrm{~h}$ on-line learning and hardcopy brochure, (2) intervention 1 plus $2 \mathrm{~h}$ classroom lesson, (3) intervention 1 plus 50 min driving lesson, (4) interventions 1, 2 and 3, and (5) intervention 1 plus a half-day workshop. The results showed that all the five interventions had apparent fuel savings and there was no statistically significant difference between them. Strömberg and Karlsson [99] compared the effects of two eco-driving strategies, namely an in-vehicle feedback system and feedback coupled with personal training. The results showed that both strategies showed $6.8 \%$ in fuel savings and no difference was observed between the two strategies. However, Schall et al. [100] reported that purely theoretical training had no effect in either the short-term or long-term, indicating the necessity of practical training elements.

Generally programs that assessed the effectiveness immediately after training demonstrated obvious improvements in fuel consumption, emissions and driving behaviours [101-105], while long-term studies showed that the training impact faded over time [106-108]. This was because the driving habits developed through many years of practice were engrained and thus hard to change in short training programs. An exception was reported by Sullman et al. [109] who found that the fuel savings 6 months after training $(16.9 \%)$ were even larger than that immediately after training (11.6\%). It should be noted that many factors could influence fuel consumption and thus the training results. For example, higher ambient temperature results in lower fuel consumption [108]. When taking this into consideration, the conclusion of an ecodriving training program changed from "effect was stable over time [103]" to "effect was gradually lost [108]". In addition, the training effect was highly heterogeneous between individuals [106]. A large percentage of trainees would exhibit no change or even become worse after training [103, 110]. A survey study showed that eco-driving interventions were more effective with high levels of pre-intervention motivation or supervisor support [111]. Studies also showed that eco-driving training was more effective under city conditions than highway conditions [106], and was more effective for manual transmission cars than automatic ones $[101,106]$. A main challenge of eco-driving training programs is the fair evaluation of the effectiveness [112]. There are many variables in a real-driving task and some would be out of control during experiments, such as changes in routes, traffic and road conditions, weather, number of passengers, and turn-over of drivers (several drivers many share one vehicle and one driver may drive different vehicles in a company or family context) [109].

The above programs were all for the existing licenced/experienced drivers while few studies were for learner drivers. One training program for learner drivers was the ECOWILL project carried out during May 2010 to April 2013 in 13 European countries. ECOWILL provided eco-driving seminars for both learner (level 1) and licensed (level 2) drivers [113]. The level 1 project integrated five golden and eight silver ecodriving rules into driving school curricula and driver tests, aiming to educate 10 million learner and novice drivers with a sustainable lasting effect $[114,115]$. The project was turned out to be very successful. By the 
end of the project, the Commission Directive 2012/36/EU made eco-driving a mandatory element of the driver test in all 28 European countries, which entered into force on 19 January 2013 [116]. Strömberg et al. [117] investigated the effect of the introduction of eco-driving into driving school curriculum in Sweden. They found that new drivers' understanding of eco-driving was at an operational level and had been clearly shaped by their driving education, while experienced drivers' understanding was broader and included strategic and tactical decisions.

Table 3. Summary of eco-driving training programs.

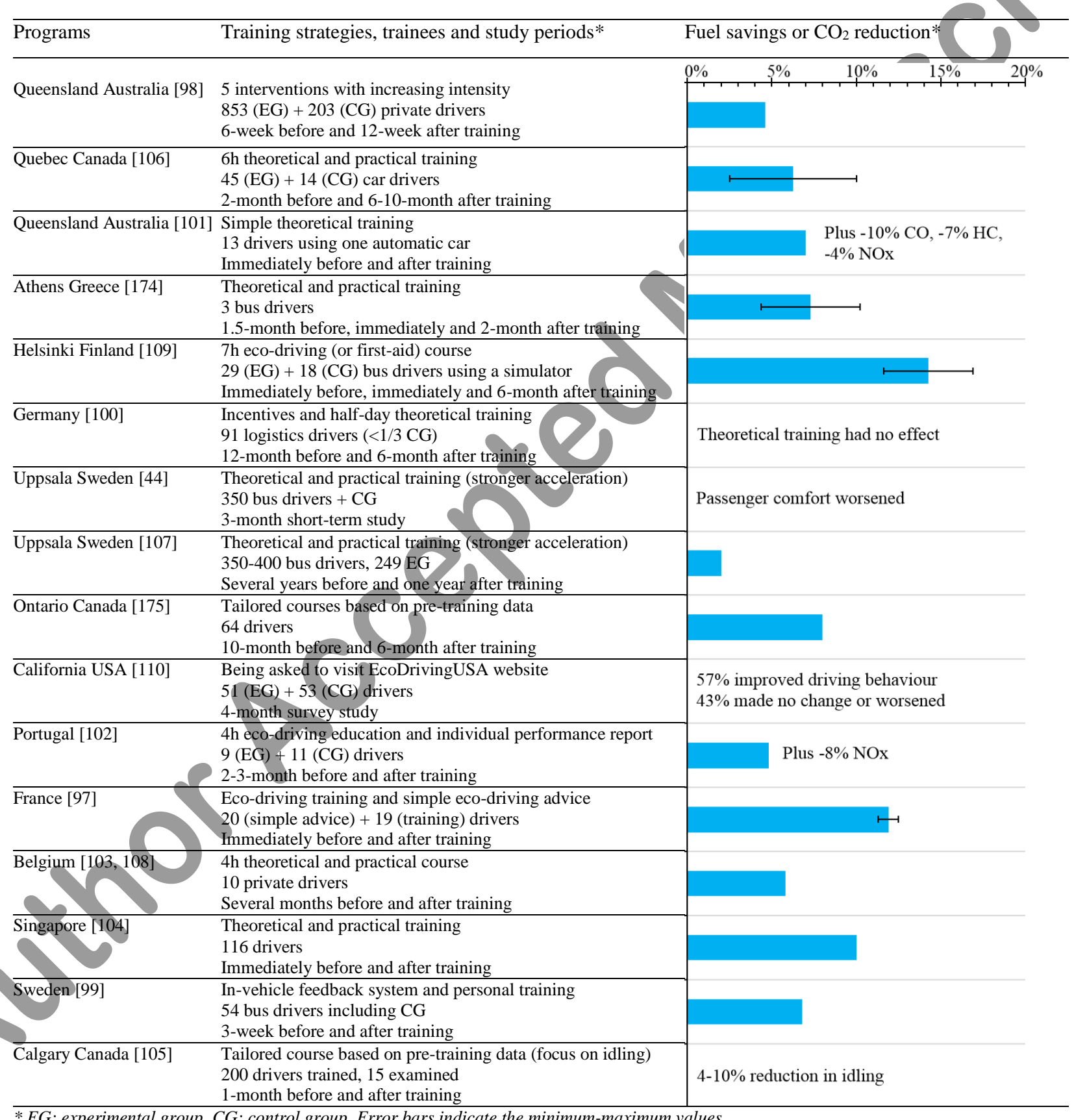

* EG: experimental group. CG: control group. Error bars indicate the minimum-maximum values. 


\subsection{In-vehicle devices}

In-vehicle eco-driving devices are an important complement to the training programs whose impacts may attenuate over time. In-vehicle devices can continuously monitor driving and provide drivers with feedback. The parameters monitored usually include fuel consumption, speed, acceleration, deceleration, idling, and road and traffic conditions. Feedback on driving performance and advice on improving it are provided to drivers based on monitoring. There are a variety of in-vehicle devices, including dashboard, smartphone applications, GPS navigation system, offline feedback system, dedicated aftermarket feedback system and haptic pedals [118]. The type of feedback also varies greatly, such as visual versus auditory versus haptic [119], real-time versus delayed [120], continuous versus intermittent [121], and general versus personalised [122]. Regardless of the types of devices and feedback, there are mainly three factors considered on in-vehicle devices' design and research, namely safety, acceptance and effectiveness.

\subsubsection{Safety}

Safety is the most important concern in a driving task. Generally, eco-driving largely overlaps with safe-driving [123]. Eco-driving recommends avoiding excessive speed and aggressive driving which are highly linked with crash risk and severity. However, the introduction of in-vehicle devices will inevitably draw some attention away from the driving task. These devices often present feedback visually. Investigations showed that a driver would spend $4-8 \%$ of the time looking at the eco-driving displays, with an average glance duration of 0.43-0.60 s and none or a few glances longer than $2 \mathrm{~s}[124,125]$. Staubach et al. [126] found that the distraction was initially very high (glance $>2$ s) but reduced over time when introducing a new in-vehicle device. The critical time-to-collision $(<15 \mathrm{~s})$ situations, hard braking and speeding were reduced by the device. Different types of in-vehicle devices would cause different distractions for drivers (e.g. visual, manual and cognitive). Studies were conducted to investigate their effects on safety. Kircher et al. [121] reported that intermittent visual eco-driving information had shorter dwell time than continuous information did. Stahl et al. [127] found that both attentional and interpretational in-vehicle displays could improve anticipatory performance for novice drivers but not for experienced drivers. Attentional display would be better for novice drivers because it had shorter and less frequent glances. Experiments on a driving simulator showed that the distraction risk caused by eco-driving task was lower than navigator and CD changing tasks which required cognitive and manual demands [128]. Jamson et al. [129] reported that continuous real-time visual feedback was the most effective but obviously reduced attention to the forward view and increased subjective workload, while haptic feedback had little effect on workload but was less effective than visual feedback. Gonder et al. [118] suggested that auditory feedback might be preferable from a driver distraction point of view and the information provided should be made as simple as possible to understand to minimise the cognitive effort required to process it. It was estimated that divers might have up to 50\% spare attentional capacity during normal driving [124]. Therefore, the distraction caused by in-vehicle devices could be minimised if the attention needed is obtained from this spare capacity. Long glances ( $>2 \mathrm{~s}$ ) away from the forward road scene at one time are associated with an increased risk of crash or near crash. The US Department of Transportation required that in-vehicle devices 
be designed so that a task can be completed by the driver with a glance away from the roadway in $\leq 2 \mathrm{~s}$ and a cumulative glance time in $\leq 12 \mathrm{~s}$ [130, 131]. These guidelines apply for both the original (Phase 1) [130] and portable and aftermarket electronic devices (Phase 2) [131] that are operated by the driver through visual and manual means.

\subsubsection{Acceptance}

Acceptance of in-vehicle eco-driving devices largely determines their effectiveness. Although most drivers are willing to adopt eco-driving skills $[132,133]$, acceptance depends strongly on the design of the system, such as the type, content, complexity and presentation of information, which should be considered seriously from an ergonomics perspective [134]. It has been clearly shown that different drivers had very different preferences on the type of information and the majority preferred simple and clear information [135]. It was found that using a display with historical feedback and incorporating learning elements increased the acceptance for learning oriented drivers, while performance oriented drivers might prefer comparative feedback and game elements [136]. Therefore, a personalised feedback could increase drivers' acceptance and motivation [136, 137]. Regarding the feedback type, auditory feedback, alone or in any combination with visual or haptic feedback, was not well accepted [138] and haptic systems were more acceptable than visual or auditory systems $[126,139]$.

\subsubsection{Effectiveness}

Fig. 3 shows the effectiveness of various types of in-vehicles eco-driving devices. As shown in Fig. 3, most of the studies used real-time (also referred as dynamic or online) feedback devices and only a few used delayed (also referred as static or offline) feedback. Both feedback types monitored the driving parameters during a trip using various data sources, such as CAN, OBD, GPS, sensors, map data or the internet. Realtime devices evaluated the driving performance and provided the feedback on improving fuel efficiency to drivers in real-time. In contrast, delayed devices provided a feedback report after the trip was completed [140, 141] or after a certain period (e.g. weekly) [120]. Experiments using field trials and driving simulators showed that real-time feedback was more effective than delayed feedback [120, 140, 142]. Real-time feedback was usually either visual, auditory, haptic or their combination. As shown in Fig. 3, the majority of studies used visual feedback devices. Visual feedback was effective to deliver detailed instructions on ecodriving while the disadvantage was that it would distract drivers and increase cognitive workload [139]. Auditory feedback required less cognitive efforts and could be complementary to visual devices $[118,139]$. However, a main drawback of auditory feedback was that drivers could not ignore it unless turning it off and might be annoyed by its prolonged use, making it the least accepted feedback [119, 126, 135, 143]. Haptic feedback provided drivers with advice through the accelerator pedal by either extra force, increased stiffness or vibration when over acceleration occurred [119, 144, 145]. Haptic feedback was effective for speed control and collision avoidance $[143,144,146]$ while the limitation was that it only provided feedback on the use of the accelerator pedal. Fig. 3 also shows that the fuel savings of field trials are typically lower than those of driving simulators and modelling. It was often reported that in-vehicle devices were more effective in urban and congested traffic than in rural and highway traffic [147-150]. However, a driving simulator 
study showed that the effectiveness of in-vehicle devices was not affected by traffic complexity in either rural or urban situations [150]. In-vehicles devices were also significantly more effective for aggressive drivers than normal or mild drivers $[141,149]$. As shown in Fig. 3, the majority of studies were carried out in very short periods (a few runs in one or two days) and their percentages of fuel savings were typically higher than $10 \%$ [148, 149, 151, 152]. However, longer term studies (several weeks or months) showed much lower fuel savings $(<8 \%)$ [120, 153-157]. This indicates that in-vehicle devices have the same limitation as training programs. That is, the effectiveness attenuates over time.

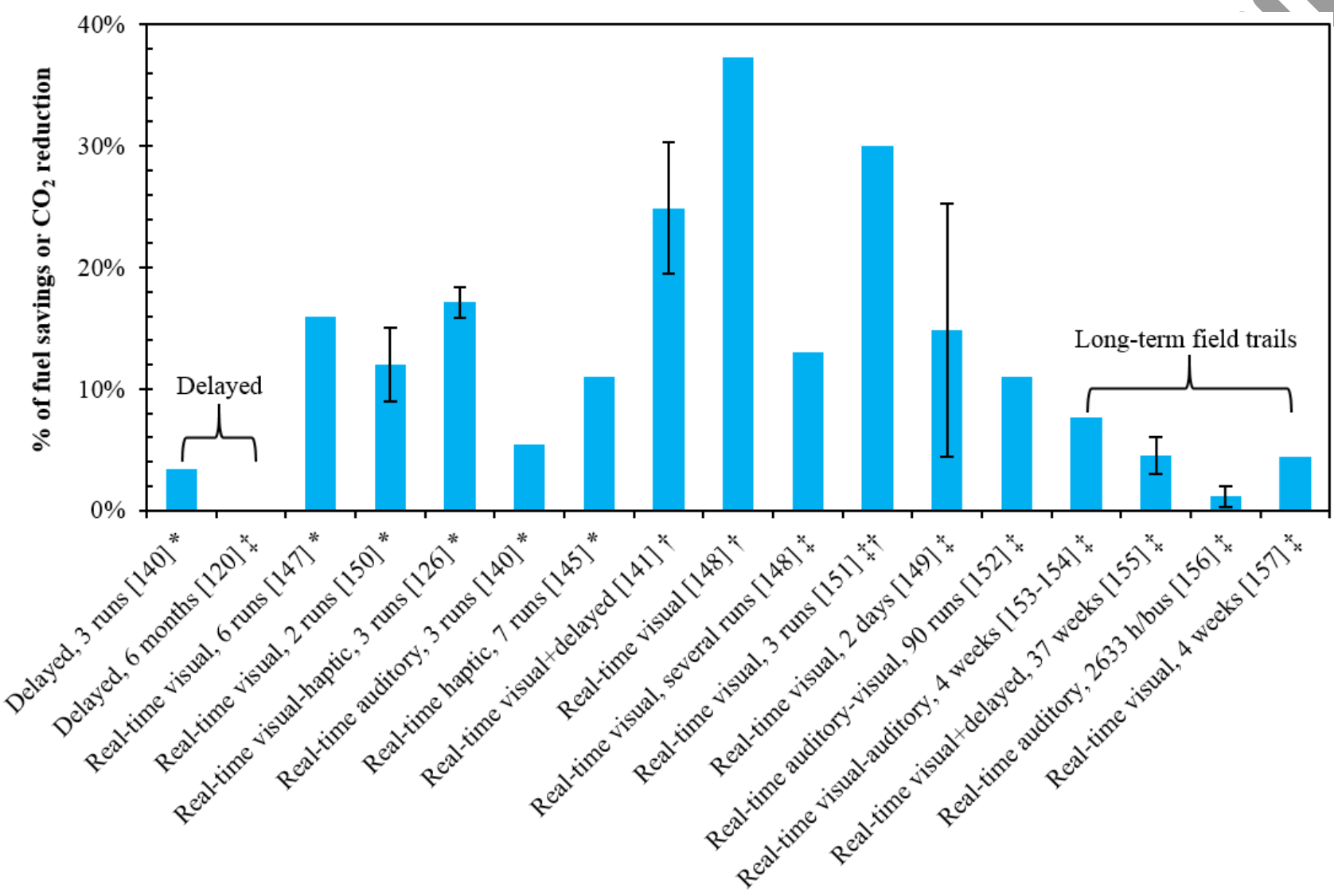

Feedback type and test method

Fig. 3. Effects of feedback type and test methods on percentages of fuel savings or $\mathrm{CO}_{2}$ reduction. Error bars indicate the minimum-maximum values reported in the studies. Symbols indicate the testing methods: *

Driving simulator, † Modelling, $¥$ Field trials, $¥ †$ Test track with no traffic. The references cited in this figure are $[120,126,140,141,145,147-157]$.

\subsection{Regulations, incentives and social marketing}

Mandatory regulations can greatly promote the implementation of eco-driving. The most important one would be the Directive 2006/126/EC [158] and its amendment Commission Directive 2012/36/EU [116] of the European Parliament and of the Council, which made eco-driving a mandatory element in driving schools and driver tests in all 28 European countries. One of the marking criteria in the driver test is driving economically and in a safe and energy-efficient way by considering the engine speed, gear changing, braking and accelerating [116]. These criteria correspond to the five golden and eight silver eco-driving rules [113]. 
Other legislative actions on eco-driving is the Engine Idling Laws in the US [56, 159] and Hong Kong [160], which restrict unnecessary idling time. Vehicles in special or emergency conditions (e.g. congestion, ambulance, fire and police) are usually exempted. Although eco-driving has attracted much attention in research globally, few regulations have been issued.

Financial incentives can be used to encourage eco-driving. Such incentives could be awards for fuelefficient public drivers or eco-driving based insurance for private drivers. Schall and Mohnen [161] investigated the effects of monetary and tangible non-monetary incentives on eco-driving in a Germany logistics company. The results showed an average reduction of 5\% in fuel consumption due to non-monetary incentive and $3.5 \%$ due to monetary incentive. Lai [162] reported a more than $10 \%$ reduction in fuel consumption after introducing a monetary reward system to bus drivers. Moreover, the benefit showed no decline over time and the money saved from fuel reduction was much more than the rewards given. Liimatainen [163] developed an eco-driving incentive system using fuel consumption data for heavy-duty vehicle drivers. The pay-as-you-drive (PAYD) or usage-based insurances (UBI) could be used to encourage eco-driving [142, 164, 165]. Several car insurance companies have adopted these schemes by using telematics to monitor people's driving behaviours and offer a discount depending on how they drive, such as Admiral's Black Box Insurance [166, 167], Progressive's Snapshot Program [168] and OnStar's Smart Driver Program [169].

It is also important to increase people's awareness and understanding on eco-driving by social marketing and advertising. For example, many drivers still believe that it is better to idle their cars several minutes before they drive or stop, which wastes a large amount of fuel [58]. Drivers also usually put a lower priority on fuel saving than time saving and convenience [134, 170], making excessive speed common on highways and reducing speed limit being extremely unpopular [18, 28]. However eco-driving does not increase travel time in urban situations and only increases slightly in rural situations, and slower driving gains safety as well. To address these barriers, social marketing and advertising of eco-driving are necessary. The eco-driving skills and benefits have been given on many governments' websites, such as US [22], Australia [21], Europe [115], Japan [171] and China [172]. However, only the motivated drivers would visit these websites and implement the eco-driving tips provided. So far very few efforts have been made for the general public

\section{Challenges and future research directions}

Road transport consumes a large amount of fossil fuel and emits significant $\mathrm{CO}_{2}$ and pollutant emissions. Driving behaviours are considered as the last major factors that determine vehicle fuel efficiency and emissions. Eco-driving is a relatively low-cost and immediate measure to significantly improve fuel efficiency. As reviewed in Section 4, it has attracted worldwide investigation and adoption in recent years. However, the effectiveness of eco-driving varies greatly due to their different research scopes, methods and factors. The following challenges should be considered and investigated as future perspectives. 
- The effects of both eco-driving training programs and in-vehicle devices were significant in the short term, but faded over time. Efforts are needed to design more effective and lasting training programs and in-vehicle devices.

- $\quad$ The benefits claimed by modelling and laboratory testing were usually much greater than those of field trials. Efforts are needed to convert the potential benefits of eco-driving from research studies into practical driving.

- The many variables in a real-world driving task make it difficult to accurately and fairly evaluate the effect of eco-driving on fuel consumption and emissions. Better experimental design is needed to focus on key variables with the most significant effects on fuel savings and emissions reduction.

- Current eco-driving skills are mostly qualitative. Investigations are needed to provide quantitative suggestions that could be integrated into hardware to generate more constant and uniform improvements.

- Most studies mainly investigated the effect of eco-driving on reducing fuel consumption and $\mathrm{CO}_{2}$ emissions, but did not cover pollutant emissions such as $\mathrm{CO}, \mathrm{HC}, \mathrm{NO}_{\mathrm{x}}$ and $\mathrm{PM}$. Trade-offs may be needed between fuel economy, pollutant emissions and travel time [173]. Different eco-driving strategies may be required for different purposes.

- $\quad$ Current eco-driving studies mostly focus on individual's driving behaviours, but lacks consideration at network levels. The recommended eco-driving styles may be constrained by surrounding vehicles or may even be unrealistic under real-driving conditions.

- Current eco-driving studies are mainly for licensed or experienced drivers, while fewer studies have been carried out for learner or novice drivers. Investigations on how eco-driving can shape and improve new drivers' driving performance are needed.

\section{Conclusions}

Eco-driving technology has been critically reviewed based on extensive scientific articles. It is found that eco-driving is a relatively low-cost and immediate measure to reduce fuel consumption and emissions significantly. The major factors influencing fuel consumption and emissions that a driver has control over during driving are acceleration/deceleration, driving speed, route choice and idling. Training programs and in-vehicle feedback devices are commonly used to implement eco-driving skills. Immediate and significant reductions in fuel consumption and $\mathrm{CO}_{2}$ emissions have been observed with a slightly increased travel time. However, the impacts of both methods can attenuate over time due to the ingrained driving habits developed over the years. This implies the necessity of developing quantitative eco-driving suggestions and integrating them into vehicle hardware to generate more constant and uniform improvements. Efforts on developing more effective, sustainable and lasting training programs and in-vehicle devices are needed for drivers. Future studies on the effect of eco-driving on pollutant emissions are required as road transport continues to be the single largest contributor of air pollution in urban areas. The effect of eco-driving on fuel consumption and emissions at network levels should also be considered. 


\section{Acknowledgements}

This work was supported by funding from Whale Logistics (Australia) Pty Ltd.

\section{References}

[1] R. Lacal Arantegui, A. Jäger-Waldau. Photovoltaics and wind status in the European Union after the Paris Agreement. Renewable and Sustainable Energy Reviews. 81 (2018) 2460-2471.

[2] A. Foley, B.M. Smyth, T. Pukšec, et al. A review of developments in technologies and research that have had a direct measurable impact on sustainability considering the Paris agreement on climate change. Renewable and Sustainable Energy Reviews. 68 (2017) 835-839.

[3] United Nations, Summary of the Paris Agreement, http://bigpicture.unfccc.int/\#content-the-parisagreemen, accessed 12.04.2018.

[4] United Nations, Paris Agreement - Status of Ratification, http://unfccc.int/paris agreement/items/9444.php, accessed 12.04.2018.

[5] United Nations, INDCs as communicated by Parties, http://www4.unfccc.int/Submissions/INDC/Submission\%20Pages/submissions.aspx, 12.04.2018.

[6] European Commission, CO2 time series 1990-2015 per region/country, http://edgar.jrc.ec.europa.eu/overview.php?v=CO2ts1990-2015, accessed 12.04.2018.

[7] A.S. Alshehry, M. Belloumi. Study of the environmental Kuznets curve for transport carbon dioxide emissions in Saudi Arabia. Renewable and Sustainable Energy Reviews. 75 (2017) 1339-1347.

[8] M. Shahbaz, N. Khraief, M.M.B. Jemaa. On the causal nexus of road transport $\mathrm{CO} 2$ emissions and macroeconomic variables in Tunisia: Evidence from combined cointegration tests. Renewable and Sustainable Energy Reviews. 51 (2015) 89-100.

[9] European Commission. Amending Regulation (EC) No 7152007 of the European Parliament and of the Council and Commission Regulation (EC) No 6922008 as regards emissions from light passenger and commercial vehicles (Euro 6). Official Journal of the European Union. 142 (2012) 16-24.

[10] L. Zhang, X. Hu, Z. Wang, et al. A review of supercapacitor modeling, estimation, and applications: A control/management perspective. Renewable and Sustainable Energy Reviews. 81 (2018) 1868-1878.

[11] Y. Huang, G. Hong, R. Huang. Investigation to charge cooling effect and combustion characteristics of ethanol direct injection in a gasoline port injection engine. Applied Energy. 160 (2015) 244-254.

[12] X. Zhen, Y. Wang. An overview of methanol as an internal combustion engine fuel. Renewable and Sustainable Energy Reviews. 52 (2015) 477-493.

[13] M. Zhou, H. Jin, W. Wang. A review of vehicle fuel consumption models to evaluate eco-driving and eco-routing. Transportation Research Part D: Transport and Environment. 49 (2016) 203-218.

[14] M. Sivak, B. Schoettle. Eco-driving: Strategic, tactical, and operational decisions of the driver that influence vehicle fuel economy. Transport Policy. 22 (2012) 96-99.

[15] Y. Xu, H. Li, H. Liu, et al. Eco-driving for transit: An effective strategy to conserve fuel and emissions. Applied Energy. 194 (2017) 784-797.

[16] M.S. Alam, A. McNabola. A critical review and assessment of Eco-Driving policy \& technology: Benefits \& limitations. Transport Policy. 35 (2014) 42-49.

[17] A. Sanguinetti, K. Kurani, J. Davies. The many reasons your mileage may vary: Toward a unifying typology of eco-driving behaviors. Transportation Research Part D: Transport and Environment. 52, Part A (2017) 73-84.

[18] J.N. Barkenbus. Eco-driving: An overlooked climate change initiative. Energy Policy. 38 (2010) 762769. 
[19] D.J. Chang, E.K. Morlok. Vehicle Speed Profiles to Minimize Work and Fuel Consumption. Journal of Transportation Engineering. 131 (2005) 173-182.

[20] T. Lee, J. Son. Relationships between Driving Style and Fuel Consumption in Highway Driving. SAE paper 2011-28-0051, 2011.

[21] Australian Department of the Environment, 10 Top Tips for Fuel Efficient Driving, https://www.environment.gov.au/settlements/transport/fuelguide/tips.html, accessed 12.04.2018.

[22] USDoE, Driving More Efficiently, http://www.fueleconomy.gov/feg/driveHabits.jsp, accessed 12.04.2018.

[23] W.W. Pulkrabek. Engineering Fundamentals of the Internal Combustion Engine. Prentice Hall, Upper Saddle River, New Jersey, 1997.

[24] I. El-Shawarby, K. Ahn, H. Rakha. Comparative field evaluation of vehicle cruise speed and acceleration level impacts on hot stabilized emissions. Transportation Research Part D: Transport and Environment. 10 (2005) 13-30.

[25] H. Wang, L. Fu, Y. Zhou, et al. Modelling of the fuel consumption for passenger cars regarding driving characteristics. Transportation Research Part D: Transport and Environment. 13 (2008) 479482.

[26] J. Wang, H.A. Rakha. Fuel consumption model for conventional diesel buses. Applied Energy. 170 (2016) 394-402.

[27] J. Ruan, P. Walker, N. Zhang. A comparative study energy consumption and costs of battery electric vehicle transmissions. Applied Energy. 165 (2016) 119-134.

[28] EEA. Do lower speed limits on motorways reduce fuel consumption and pollutant emissions? 2011.

[29] F. Mensing, E. Bideaux, R. Trigui, et al. Trajectory optimization for eco-driving taking into account traffic constraints. Transportation Research Part D: Transport and Environment. 18 (2013) 55-61.

[30] S. Birrell, J. Taylor, A. McGordon, et al. Analysis of three independent real-world driving studies: A data driven and expert analysis approach to determining parameters affecting fuel economy. Transportation Research Part D: Transport and Environment. 33 (2014) 74-86.

[31] M. Wang, W. Daamen, S. Hoogendoorn, et al. Potential impacts of ecological adaptive cruise control systems on traffic and environment. IET Intelligent Transport Systems. 8 (2014) 77-86.

[32] A. D'Amato, F. Donatantonio, I. Arsie, et al. Development of a Cruise Controller Based on Current Road Load Information with-Integrated Control of Variable Velocity Set-Point and Gear Shifting. SAE paper 2017-01-0089, 2017.

[33] B. Saerens, H.A. Rakha, M. Diehl, et al. A methodology for assessing eco-cruise control for passenger vehicles. Transportation Research Part D: Transport and Environment. 19 (2013) 20-27.

[34] S.E. Li, Q. Guo, L. Xin, et al. Fuel-Saving Servo-Loop Control for an Adaptive Cruise Control System of Road Vehicles With Step-Gear Transmission. IEEE Transactions on Vehicular Technology. 66 (2017) 2033-2043.

[35] X. He, H.X. Liu, X. Liu. Optimal vehicle speed trajectory on a signalized arterial with consideration of queue. Transportation Research Part C: Emerging Technologies. 61 (2015) 106-120.

[36] X. Xiang, K. Zhou, W.B. Zhang, et al. A Closed-Loop Speed Advisory Model With Driver's Behavior Adaptability for Eco-Driving. IEEE Transactions on Intelligent Transportation Systems. 16 (2015) 3313-3324.

[37] S. Kundu, S. Kundu. Flexible Vehicle Speed Control Algorithms for Eco-Driving. 2015 IEEE 82nd Vehicular Technology Conference (VTC2015-Fall), 2015.

[38] S. Kundu, A. Wagh, C. Qiao, et al. Vehicle speed control algorithms for eco-driving. 2013 International Conference on Connected Vehicles and Expo (ICCVE), 2013.

[39] S. Xu, S.E. Li, H. Peng, et al. Fuel-Saving Cruising Strategies for Parallel HEVs. IEEE Transactions on Vehicular Technology. 65 (2016) 4676-4686. 
[40] H. Larsson, E. Ericsson. The effects of an acceleration advisory tool in vehicles for reduced fuel consumption and emissions. Transportation Research Part D: Transport and Environment. 14 (2009) 141-146.

[41] IEE. Ecodriven Campaign Catalogue for European Eco-driving \& Traffic Safety Campaigns. 2008.

[42] H. Xia, K. Boriboonsomsin, M. Barth. Dynamic Eco-Driving for Signalized Arterial Corridors and Its Indirect Network-Wide Energy/Emissions Benefits. Journal of Intelligent Transportation Systems. 17 (2013) 31-41.

[43] B. Saerens, E. Van den Bulck. Calculation of the minimum-fuel driving control based on Pontryagin's maximum principle. Transportation Research Part D: Transport and Environment. 24 (2013) 89-97.

[44] A.E. af Wåhlberg. Short-term effects of training in economical driving: Passenger comfort and driver acceleration behavior. International Journal of Industrial Ergonomics. 36 (2006) 151-163.

[45] E. Ericsson. Independent driving pattern factors and their influence on fuel-use and exhaust emission factors. Transportation Research Part D: Transport and Environment. 6 (2001) 325-345.

[46] L. Pelkmans, D. De Keukeleere, H. Bruneel, et al. Influence of Vehicle Test Cycle Characteristics on Fuel Consumption and Emissions of City Buses. SAE Paper 2001-01-2002, 2001.

[47] C. Chen, C. Huang, Q. Jing, et al. On-road emission characteristics of heavy-duty diesel vehicles in Shanghai. Atmospheric Environment. 41 (2007) 5334-5344.

[48] J. Gallus, U. Kirchner, R. Vogt, et al. Impact of driving style and road grade on gaseous exhaust emissions of passenger vehicles measured by a Portable Emission Measurement System (PEMS). Transportation Research Part D: Transport and Environment. 52, Part A (2017) 215-226.

[49] A. Wang, Y. Ge, J. Tan, et al. On-road pollutant emission and fuel consumption characteristics of buses in Beijing. Journal of Environmental Sciences. 23 (2011) 419-426.

[50] I.M. Berry. The Effects of Driving Style and Vehicle Performance on the Real-World Fuel Consumption of U.S. Light-Duty Vehicles. Degree of Master. Department of Mechanical Engineering, Massachusetts Institute of Technology. 2010.

[51] E. Choi, E. Kim. Critical aggressive acceleration values and models for fuel consumption when starting and driving a passenger car running on LPG. International Journal of Sustainable Transportation. 11 (2017) 395-405

[52] J. Sun, H.X. Liu. Stochastic eco-routing in a signalized traffic network. Transportation Research Part C: Emerging Technologies. 59 (2015) 32-47.

[53] E. Hellström, M. Ivarsson, J. Åslund, et al. Look-ahead control for heavy trucks to minimize trip time and fuel consumption. Control Engineering Practice. 17 (2009) 245-254.

[54] S.A. Birrell, M.S. Young, A.M. Weldon. Vibrotactile pedals: provision of haptic feedback to support economical driving. Ergonomics. 56 (2013) 282-292.

[55] Argonne National Laboratory, Idling Reduction Savings Calculator, http://www.anl.gov/sites/anl.gov/files/idling_worksheet.pdf, accessed 12.04.2018.

[56] USDoE. Idling Reduction for Personal Vehicles. 2015.

[57] S.M.A. Rahman, H.H. Masjuki, M.A. Kalam, et al. Impact of idling on fuel consumption and exhaust emissions and available idle-reduction technologies for diesel vehicles - A review. Energy Conversion and Management. 74 (2013) 171-182.

[58] A.R. Carrico, P. Padgett, M.P. Vandenbergh, et al. Costly myths: An analysis of idling beliefs and behavior in personal motor vehicles. Energy Policy. 37 (2009) 2881-2888.

[59] D. Maamria, K. Gillet, G. Colin, et al. Which methodology is more appropriate to solve Eco-driving Optimal Control Problem for conventional vehicles? 2016 IEEE Conference on Control Applications (CCA), 2016.

[60] G. Mahler, A. Vahidi. An Optimal Velocity-Planning Scheme for Vehicle Energy Efficiency Through Probabilistic Prediction of Traffic-Signal Timing. IEEE Transactions on Intelligent Transportation Systems. 15 (2014) 2516-2523. 
[61] S. Mandava, K. Boriboonsomsin, M. Barth. Arterial velocity planning based on traffic signal information under light traffic conditions. 12th International IEEE Conference on Intelligent Transportation Systems, 2009.

[62] M. Li, K. Boriboonsomsin, G. Wu, et al. Traffic Energy and Emission Reductions at Signalized Intersections: A Study of the Benefits of Advanced Driver Information. International Journal of Intelligent Transportation Systems Research. 7 (2009) 49-58.

[63] E. Yao, Y. Song. Study on Eco-Route Planning Algorithm and Environmental Impact Assessment. Journal of Intelligent Transportation Systems. 17 (2013) 42-53.

[64] Y. Nie, Q. Li. An eco-routing model considering microscopic vehicle operating conditions. Transportation Research Part B: Methodological. 55 (2013) 154-170.

[65] S. Lee, J. Cherry, M. Safoutin, et al. Modeling and Validation of 12V Lead-Acid Battery for StopStart Technology. SAE paper 2017-01-1211, 2017.

[66] M.A. Abas, S.F. Zainal Abidin, S. Rajoo, et al. Evaluation Between Engine Stop/Start and Cylinder Deactivation Technologies Under Southeast Asia Urban Driving Condition. SAE paper 2017-01-0986, 2017.

[67] N. Fonseca, J. Casanova, M. Valdés. Influence of the stop/start system on CO2 emissions of a diesel vehicle in urban traffic. Transportation Research Part D: Transport and Environment. 16 (2011) 194200.

[68] M. Masikos, K. Demestichas, E. Adamopoulou, et al. Energy-efficient routing based on vehicular consumption predictions of a mesoscopic learning model. Applied Soft Computing. 28 (2015) 114-124.

[69] K. Boriboonsomsin, M.J. Barth, W. Zhu, et al. Eco-Routing Navigation System Based on Multisource Historical and Real-Time Traffic Information. IEEE Transactions on Intelligent Transportation Systems. 13 (2012) 1694-1704.

[70] K. Ahn, H. Rakha. The effects of route choice decisions on vehicle energy consumption and emissions. Transportation Research Part D: Transport and Environment. 13 (2008) 151-167.

[71] E. Ericsson, H. Larsson, K. Brundell-Freij. Optimizing route choice for lowest fuel consumption Potential effects of a new driver support tool. Transportation Research Part C: Emerging Technologies. 14 (2006) 369-383.

[72] W. Zeng, T. Miwa, T. Morikawa Prediction of vehicle CO2 emission and its application to ecorouting navigation. Transportation Research Part C: Emerging Technologies. 68 (2016) 194-214.

[73] Y. Kuo. Using simulated annealing to minimize fuel consumption for the time-dependent vehicle routing problem. Computers \& Industrial Engineering. 59 (2010) 157-165.

[74] K. Ahn, H.A. Rakha. Network-wide impacts of eco-routing strategies: A large-scale case study. Transportation Research Part D: Transport and Environment. 25 (2013) 119-130.

[75] Q. Jin, G. Wu, K. Boriboonsomsin, et al. Power-Based Optimal Longitudinal Control for a Connected Eco-Driving System. IEEE Transactions on Intelligent Transportation Systems. 17 (2016) 2900-2910.

[76] K. Boriboonsomsin, M. Barth. Impacts of Road Grade on Fuel Consumption and Carbon Dioxide Emissions Evidenced by Use of Advanced Navigation Systems. Transportation Research Record: Journal of the Transportation Research Board. 2139 (2009) 21-30.

[77] J.M. Bandeira, T. Fontes, S.R. Pereira, et al. Assessing the Importance of Vehicle Type for the Implementation of Eco-routing Systems. Transportation Research Procedia. 3 (2014) 800-809.

[78] H.A. Rakha, K. Ahn, K. Moran. INTEGRATION Framework for Modeling Eco-routing Strategies: Logic and Preliminary Results. International Journal of Transportation Science and Technology. 1 (2012) 259-274.

[79] A. Garcia-Castro, A. Monzon, C. Valdes, et al. Modeling different penetration rates of eco-driving in urban areas: Impacts on traffic flow and emissions. International Journal of Sustainable Transportation. 11 (2017) 282-294. 
[80] H. Jiang, J. Hu, S. An, et al. Eco approaching at an isolated signalized intersection under partially connected and automated vehicles environment. Transportation Research Part C: Emerging Technologies. 79 (2017) 290-307.

[81] R. Farrington, J. Rugh. Impact of vehicle air-conditioning on fuel consumption, tailpipe emissions, and electric vehicle range. The Earth Technologies Forum, 2000.

[82] V.H. Johnson. Fuel Used for Vehicle Air Conditioning: A State-by-State Thermal Comfort-Based Approach. SAE Paper 2002-01-1957, 2002.

[83] S. Huff, B. West, J. Thomas. Effects of Air Conditioner Use on Real-World Fuel Economy. SAE paper 2013-01-0551, 2013.

[84] S.H. Jacobson, L.A. McLay. The Economic Impact of Obesity on Automobile Fuel Consumption. The Engineering Economist. 51 (2006) 307-323.

[85] USEPA, Vehicle and Fuel Emissions Testing - Engine Testing Regulations, https://www.epa.gov/vehicle-and-fuel-emissions-testing/engine-testing-regulations\#tengine-testprocedures, accessed 12.04.2018.

[86] V. Franco, M. Kousoulidou, M. Muntean, et al. Road vehicle emission factors development: A review. Atmospheric Environment. 70 (2013) 84-97.

[87] Economic Commission. Regulation No 101 of the Economic Commission for Europe of the United Nations (UN/ECE) - Uniform provisions concerning the approval of passenger cars powered by an internal combustion engine only, or powered by a hybrid electric power train. Official Journal of the European Union. 158 (2007) 34-105.

[88] G. Mellios, S. Hausberger, M. Keller, et al. Parameterisation of fuel consumption and CO2 emissions of passenger cars and light commercial vehicles for modelling purposes. 2011.

[89] L. Meuleners, M. Fraser. A validation study of driving errors using a driving simulator. Transportation Research Part F: Traffic Psychology and Behaviour. 29 (2015) 14-21.

[90] A. Helland, S. Lydersen, L.-E. Lervåg, et al Driving simulator sickness: Impact on driving performance, influence of blood alcohol concentration, and effect of repeated simulator exposures. Accident Analysis \& Prevention. 94 (2016) 180-187.

[91] Y. Huang, B. Organ, J.L. Zhou, et al. Remote sensing of on-road vehicle emissions: Mechanism, applications and a case study from Hong Kong. Atmospheric Environment. 182 (2018) 58-74.

[92] European Commission. COMMISSION REGULATION (EU) 2016/646 of 20 April 2016 amending Regulation (EC) No 692/2008 as regards emissions from light passenger and commercial vehicles (Euro 6). Official Journal of the European Union. 109 (2016) 1-22.

[93] USEPA, Vehicle Emissions On-Board Diagnostics (OBD), https://www.epa.gov/state-and-localtransportation/2ehicle-emissions-board-diagnostics-obd, accessed 12.04.2018.

[94] M. Zhou, H. Jin. Development of a transient fuel consumption model. Transportation Research Part D: Transport and Environment. 51 (2017) 82-93.

[95] J. Thomas, H.-L. Hwang, B. West, et al. Predicting Light-Duty Vehicle Fuel Economy as a Function of Highway Speed. SAE Int J Passeng Cars - Mech Syst. 6 (2013) 859-875.

[96] O. Orfila, C. Freitas Salgueiredo, G. Saint Pierre, et al. Fast computing and approximate fuel consumption modeling for Internal Combustion Engine passenger cars. Transportation Research Part D: Transport and Environment. 50 (2017) 14-25.

[97] C. Andrieu, G.S. Pierre. Comparing Effects of Eco-driving Training and Simple Advices on Driving Behavior. Procedia - Social and Behavioral Sciences. 54 (2012) 211-220.

[98] I. Jeffreys, G. Graves, M. Roth. Evaluation of eco-driving training for vehicle fuel use and emission reduction: A case study in Australia. Transportation Research Part D: Transport and Environment. 60 (2018) 85-91. 
[99] H.K. Strömberg, I.C.M. Karlsson. Comparative effects of eco-driving initiatives aimed at urban bus drivers - Results from a field trial. Transportation Research Part D: Transport and Environment. 22 (2013) 28-33.

[100] D.L. Schall, M. Wolf, A. Mohnen. Do effects of theoretical training and rewards for energy-efficient behavior persist over time and interact? A natural field experiment on eco-driving in a company fleet. Energy Policy. 97 (2016) 291-300.

[101] G.S. Larue, H. Malik, A. Rakotonirainy, et al. Fuel consumption and gas emissions of an automatic transmission vehicle following simple eco-driving instructions on urban roads. IET Intelligent Transport Systems. 8 (2014) 590-597.

[102] C.C. Rolim, P.C. Baptista, G.O. Duarte, et al. Impacts of On-board Devices and Training on Light Duty Vehicle Driving Behavior. Procedia - Social and Behavioral Sciences. 111 (2014) 711-720.

[103] B. Beusen, S. Broekx, T. Denys, et al. Using on-board logging devices to study the longer-term impact of an eco-driving course. Transportation Research Part D: Transport and Environment. 14 (2009) 514520.

[104] S.-H. Ho, Y.-D. Wong, V.W.-C. Chang. What can eco-driving do for sustainable road transport? Perspectives from a city (Singapore) eco-driving programme. Sustainable Cities and Society. 14 (2015) 82-88.

[105] M. Rutty, L. Matthews, J. Andrey, et al. Eco-driver training within the City of Calgary's municipal fleet: Monitoring the impact. Transportation Research Part D: Transport and Environment. 24 (2013) 44-51.

[106] P. Barla, M. Gilbert-Gonthier, M.A. Lopez Castro, et al. Eco-driving training and fuel consumption: Impact, heterogeneity and sustainability. Energy Economics. 62 (2017) 187-194.

[107] A.E. af Wåhlberg. Long-term effects of training in economical driving: Fuel consumption, accidents, driver acceleration behavior and technical feedback. International Journal of Industrial Ergonomics. 37 (2007) 333-343.

[108] B. Degraeuwe, B. Beusen. Corrigendum on the paper "Using on-board data logging devices to study the longer-term impact of an eco-driving course". Transportation Research Part D: Transport and Environment. 19 (2013) 48-49.

[109] M.J.M. Sullman, L. Dorn, P. Niemi. Eco-driving training of professional bus drivers - Does it work? Transportation Research Part C: Emerging Technologies. 58 (2015) 749-759.

[110] E. Martin, N.D. Chan, S.A. Shaheen. Understanding How Ecodriving Public Education Can Result in Reduced Fuel Use and Greenhouse Gas Emissions. Transportation Research Board Annual Meeting, 2012.

[111] L.R. Mansfield, F. Guros, D.M. Truxillo, et al. Individual and contextual variables enhance transfer for a workplace eco-driving intervention. Transportation Research Part F: Traffic Psychology and Behaviour. 37 (2016) 138-143.

[112] X.G. Pañeda, R. Garcia, G. Diaz, et al. Formal characterization of an efficient driving evaluation process for companies of the transport sector. Transportation Research Part A: Policy and Practice. 94 (2016) 431-445.

[113] IEE. Eco-driving, Short-duration training for licensed drivers and integration into driving education for learner drivers - Experiences and results from the ECOWILL project. 2013.

[114] IEE, ECOWILL brochure for driving schools, https://ec.europa.eu/energy/intelligent/projects/sites/ieeprojects/files/projects/documents/ecowill brochure for driving schools en.pdf, accessed 12.04.2018.

[115] IEE, Eco-driving - Widespread Implementation for Learners and Licensed Drivers, https://ec.europa.eu/energy/intelligent/projects/en/projects/ecowill, accessed 12.04.2018.

[116] European Commission. COMMISSION DIRECTIVE 2012/36/EU of 19 November 2012 amending Directive 2006/126/EC of the European Parliament and of the Council on driving licences. Official Journal of the European Union. 321 (2012) 54-58. 
[117] H. Strömberg, I.C.M. Karlsson, O. Rexfelt. Eco-driving: Drivers' understanding of the concept and implications for future interventions. Transport Policy. 39 (2015) 48-54.

[118] J. Gonder, M. Earleywine, W. Sparks. Analyzing Vehicle Fuel Saving Opportunities through Intelligent Driver Feedback. SAE Int J Passeng Cars - Electron Electr Syst. 5 (2012) 450-461.

[119] A.H. Jamson, D.L. Hibberd, N. Merat. Interface design considerations for an in-vehicle eco-driving assistance system. Transportation Research Part C: Emerging Technologies. 58, Part D (2015) 642656.

[120] C. Rolim, P. Baptista, G. Duarte, et al. Impacts of delayed feedback on eco-driving behavior and resulting environmental performance changes. Transportation Research Part F: Traffic Psychology and Behaviour. 43 (2016) 366-378.

[121] K. Kircher, C. Fors, C. Ahlstrom. Continuous versus intermittent presentation of visual eco-driving advice. Transportation Research Part F: Traffic Psychology and Behaviour. 24 (2014) 27-38.

[122] E. Gilman, A. Keskinarkaus, S. Tamminen, et al. Personalised assistance for fuel-efficient driving. Transportation Research Part C: Emerging Technologies. 58, Part D (2015) 681-705.

[123] M.S. Young, S.A. Birrell, N.A. Stanton. Safe driving in a green world: A review of driver performance benchmarks and technologies to support 'smart' driving. Applied Ergonomics. 42 (2011) 533-539.

[124] S.A. Birrell, M. Fowkes. Glance behaviours when using an in-vehicle smart driving aid: A real-world, on-road driving study. Transportation Research Part F: Traffic Psychology and Behaviour. 22 (2014) $113-125$.

[125] C. Ahlstrom, K. Kircher. Changes in glance behaviour when using a visual eco-driving system - A field study. Applied Ergonomics. 58 (2017) 414-423.

[126] M. Staubach, N. Schebitz, F. Köster, et al. Evaluation of an eco-driving support system. Transportation Research Part F: Traffic Psychology and Behaviour. 27, Part A (2014) 11-21.

[127] P. Stahl, B. Donmez, G.A. Jamieson. Supporting anticipation in driving through attentional and interpretational in-vehicle displays. Accident Analysis \& Prevention. 91 (2016) 103-113.

[128] H. Rouzikhah, M. King, A. Rakotonirainy, Examining the effects of an eco-driving message on driver distraction. Accident Analysis \& Prevention. 50 (2013) 975-983.

[129] S.L. Jamson, D.L. Hibberd, A.H. Jamson. Drivers' ability to learn eco-driving skills; effects on fuel efficient and safe driving behaviour. Transportation Research Part C: Emerging Technologies. 58, Part D (2015) 657-668.

[130] USDoT. Visual-Manual NHTSA Driver Distraction Guidelines for In-Vehicle Electronic Devices, National Highway Traffic Safety Administration (NHTSA), Docket No. NHTSA-2010-0053. Federal Register. 78 (2014) 24818-24890.

[131] USDoT. Visual-Manual NHTSA Driver Distraction Guidelines for Portable and Aftermarket Devices, National Highway Traffic Safety Administration (NHTSA), Docket No. NHTSA-2013-0137. Federal Register. 81 (2016) 87656-87683.

[132] R. Thijssen, T. Hofman, J. Ham. Ecodriving acceptance: An experimental study on anticipation behavior of truck drivers. Transportation Research Part F: Traffic Psychology and Behaviour. 22 (2014) 249-260.

[133] R.C. McIlroy, N.A. Stanton. What do people know about eco-driving? Ergonomics. 60 (2016) 754769.

[134] J. Harvey, N. Thorpe, R. Fairchild. Attitudes towards and perceptions of eco-driving and the role of feedback systems. Ergonomics. 56 (2013) 507-521.

[135] C. Fors, K. Kircher, C. Ahlström. Interface design of eco-driving support systems - Truck drivers' preferences and behavioural compliance. Transportation Research Part C: Emerging Technologies. 58, Part D (2015) 706-720. 
[136] R.F.T. Brouwer, A. Stuiver, T. Hof, et al. Personalised feedback and eco-driving: An explorative study. Transportation Research Part C: Emerging Technologies. 58, Part D (2015) 760-771.

[137] T. Stillwater, K.S. Kurani. Drivers discuss ecodriving feedback: Goal setting, framing, and anchoring motivate new behaviors. Transportation Research Part F: Traffic Psychology and Behaviour. 19 (2013) 85-96.

[138] R.C. McIlroy, N.A. Stanton, L. Godwin, et al. Encouraging Eco-Driving With Visual, Auditory, and Vibrotactile Stimuli. IEEE Transactions on Human-Machine Systems. 47 (2016) 661-672.

[139] D.L. Hibberd, A.H. Jamson, S.L. Jamson. The design of an in-vehicle assistance system to support eco-driving. Transportation Research Part C: Emerging Technologies. 58, Part D (2015) 732-748.

[140] X. Zhao, Y. Wu, J. Rong, et al. Development of a driving simulator based eco-driving support system. Transportation Research Part C: Emerging Technologies. 58, Part D (2015) 631-641.

[141] J. Rios-Torres, P. Sauras-Perez, R. Alfaro, et al. Eco-Driving System for Energy Efficient Driving of an Electric Bus. SAE Int J Passeng Cars - Electron Electr Syst. 8 (2015) 79-89.

[142] C. Dijksterhuis, B. Lewis-Evans, B. Jelijs, et al. The impact of immediate or delayed feedback on driving behaviour in a simulated Pay-As-You-Drive system. Accident Analysis \& Prevention. 75 (2015) 93-104.

[143] E. Adell, A. Várhelyi, M. Hjälmdahl. Auditory and haptic systems for in-car speed management - A comparative real life study. Transportation Research Part F: Traffic Psychology and Behaviour. 11 (2008) 445-458.

[144] M. Mulder, M. Mulder, M.M. van Paassen, et al. Haptic gas pedal feedback. Ergonomics. 51 (2008) 1710-1720.

[145] R.C. McIlroy, N.A. Stanton, L. Godwin. Good vibrations: Using a haptic accelerator pedal to encourage eco-driving. Transportation Research Part F: Traffic Psychology and Behaviour. 46, Part A (2017) 34-46.

[146] J.D. Lee, D.V. McGehee, T.L. Brown, et al. Driver sensitivity to brake pulse duration and magnitude. Ergonomics. 50 (2007) 828-836.

[147] M. van der Voort, M.S. Dougherty, M. van Maarseveen. A prototype fuel-efficiency support tool. Transportation Research Part C: Emerging Technologies. 9 (2001) 279-296.

[148] M. Barth, K. Boriboonsomsin. Energy and emissions impacts of a freeway-based dynamic eco-driving system. Transportation Research Part D: Transport and Environment. 14 (2009) 400-410.

[149] S.Y. Kim, D.J. Shin, H.J. Yoon, et al. Development of Eco-Driving Guide System. SAE paper 201128-0034, 2011.

[150] C.P. Rommerskirchen, M. Helmbrecht, K.J. Bengler. The Impact of an Anticipatory Eco-Driver Assistant System in Different Complex Driving Situations on the Driver Behavior. IEEE Intelligent Transportation Systems Magazine. 6 (2014) 45-56.

[151] O. Orfila, G. Saint Pierre, M. Messias. An android based ecodriving assistance system to improve safety and efficiency of internal combustion engine passenger cars. Transportation Research Part C: Emerging Technologies. 58, Part D (2015) 772-782.

[152] V.C. Magaña, M. Muñoz-Organero. Artemisa: A Personal Driving Assistant for Fuel Saving. IEEE Transactions on Mobile Computing. 15 (2016) 2437-2451.

[153] C. Vagg, C.J. Brace, D. Hari, et al. Development and Field Trial of a Driver Assistance System to Encourage Eco-Driving in Light Commercial Vehicle Fleets. IEEE Transactions on Intelligent Transportation Systems. 14 (2013) 796-805.

[154] C. Vagg, C. Brace, D. Hari, et al. A Driver Advisory Tool to Reduce Fuel Consumption. SAE 201201-2087, 2013.

[155] B. Caulfield, W. Brazil, K. Ni Fitzgerald, et al. Measuring the success of reducing emissions using an on-board eco-driving feedback tool. Transportation Research Part D: Transport and Environment. 32 (2014) 253-262. 
[156] C. Rolim, P. Baptista, G. Duarte, et al. Real-Time Feedback Impacts on Eco-Driving Behavior and Influential Variables in Fuel Consumption in a Lisbon Urban Bus Operator. IEEE Transactions on Intelligent Transportation Systems. 18 (2017) 3061-3071.

[157] T. Stillwater, K.S. Kurani, P.L. Mokhtarian. The combined effects of driver attitudes and in-vehicle feedback on fuel economy. Transportation Research Part D: Transport and Environment. 52, Part A (2017) 277-288.

[158] European Commission. Directive 2006/126/EC of the European Parliament and of the Council of 20 December 2006. Official Journal of the European Union. 409 (2006) 18-60.

[159] USDoE, Database of Idling Regulations, https://cleancities.energy.gov/technical-assistance/idlebox/, accessed 12.04.2018.

[160] HKEPD, The Statutory Ban against Idling of Motor Vehicle Engines, http://www.epd.gov.hk/epd/english/environmentinhk/air/prob_solutions/idling_prohibition.html, accessed 12.04.2018.

[161] D.L. Schall, A. Mohnen. Incentivizing energy-efficient behavior at work: An empirical investigation using a natural field experiment on eco-driving. Applied Energy. 185, Part 2 (2017) 1757-1768.

[162] W.-T. Lai. The effects of eco-driving motivation, knowledge and reward intervention on fuel efficiency. Transportation Research Part D: Transport and Environment. 34 (2015) 155-160.

[163] H. Liimatainen. Utilization of Fuel Consumption Data in an Ecodriving Incentive System for HeavyDuty Vehicle Drivers. IEEE Transactions on Intelligent Transportation Systems. 12 (2011) 1087-1095.

[164] C. Dijksterhuis, B. Lewis-Evans, B. Jelijs, et al. In-car usage-based insurance feedback strategies. A comparative driving simulator study. Ergonomics. 59 (2016) 1158-1170.

[165] Y. Li, J. Zheng, Z. Li, et al. Re-estimating CO2 emission factors for gasoline passenger cars adding driving behaviour characteristics - A case study of Beijing. Energy Policy. 102 (2017) 353-361.

[166] Admiral, Black Box Insurance - LittleBox in six simple steps, http://www.admiral.com/black-boxinsurance/\#, accessed 12.04.2018.

[167] GreenRoad, GreenRoad and Admiral Partner to Launch 'First Pay How You Drive' Insurance Scheme, http://greenroad.com/greenroad-and-admiral-partner-to-launch-first-pay-how-you-drive-insurancescheme/, accessed 12.04.2018.

[168] Progressive, Snapshot means BIG discounts for good drivers, https://www.progressive,com/auto/snapshot/, accessed 12.04.2018.

[169] OnStar, Discover the Advantages of Being an OnStar Smart Driver, https://www.onstar.com/us/en/smart_driver/, accessed 12.04.2018.

[170] E. Dogan, L. Steg, P. Delhomme. The influence of multiple goals on driving behavior: The case of safety, timesaving, and fuel saving. Accident Analysis \& Prevention. 43 (2011) 1635-1643.

[171] Japanese Ministry of Economy Trade and Industry, November is Eco-Drive Promotion Month, http://www.meti.go.jp/english/press/2015/1030_04.html, accessed 12.04.2018.

[172] Chinese Ministry of Transport, Handbook of Eco-driving, http./(zizhan.mot.gov.cn/sj/yunshs/xinwendt_yshs/201411/t20141114_1724807.html, $\quad$ accessed 12.04.2018.

[173] F. Mensing, E. Bideaux, R. Trigui, et al. Eco-driving: An economic or ecologic driving style? Transportation Research Part C: Emerging Technologies. 38 (2014) 110-121.

[174] M. Zarkadoula, G. Zoidis, E. Tritopoulou. Training urban bus drivers to promote smart driving: A note on a Greek eco-driving pilot program. Transportation Research Part D: Transport and Environment. 12 (2007) 449-451.

[175] M. Rutty, L. Matthews, D. Scott, et al. Using vehicle monitoring technology and eco-driver training to reduce fuel use and emissions in tourism: a ski resort case study. Journal of Sustainable Tourism. 22 (2014) 787-800. 